\title{
Attitudes toward Migrants in a Highly-Impacted Economy: Evidence from the Syrian Refugee Crisis in Jordan
}

\author{
Ala' Alrababa'h ${ }^{1,2, \star}$, Andrea Dillon ${ }^{2, \star}$, Scott Williamson ${ }^{1,2, \star}$, \\ Jens Hainmueller ${ }^{1,2,3}$, Dominik Hangartner ${ }^{2,4,5}$, Jeremy Weinstein ${ }^{1,2}$ \\ ${ }^{1}$ Department of Political Science, Stanford University \\ ${ }^{2}$ Immigration Policy Lab, Stanford University and ETH Zurich \\ ${ }^{3}$ Graduate School of Business, Stanford University \\ ${ }^{4}$ Center for International and Comparative Studies, ETH Zurich \\ ${ }^{5}$ Department of Government, London School of Economics and Political Science
}

March 31, 2020

\begin{abstract}
With international migration at a record high, a burgeoning literature has explored the drivers of public attitudes toward migrants. However, most studies to date have focused on developed countries, which have relatively fewer migrants and more capacity to absorb them. We address this sample bias by conducting a survey of public attitudes toward Syrians in Jordan, a developing country with one of the largest shares of refugees. Our analysis indicates that neither personal nor community-level exposure to the economic impact of the refugee crisis is associated with anti-migrant sentiments among natives. Further, an embedded conjoint experiment validated with qualitative evidence demonstrates the relative importance of humanitarian and cultural concerns over economic ones. Taken together, our findings weaken the case for egocentric and sociotropic economic concerns as critical drivers of anti-migrant attitudes, and demonstrate how humanitarian motives can sustain support for refugees when host and migrant cultures are similar.
\end{abstract}

\footnotetext{
* These authors contributed equally. We acknowledge funding from the Swiss Network for International Studies, the Ford Foundation, and the Stanford Center for International Conflict and Negotiation. We are also grateful to Kirk Bansak, Duncan Lawrence, Rebecca Wolfe, participants at the 2018 International Migration and Refugee Law Workshop at the University of California, Berkeley, and participants in our APSA 2017 panel for their feedback and support.
} 


\section{Introduction}

Countries across the globe are struggling to cope with the highest levels of forced displacement recorded since the end of World War II. Pushed out of their countries of origin due to protracted conflict and poverty, more than 28 million people are currently living as refugees. This increase in migration has led to social tensions and political conflict in many host societies in recent years. For example, in Germany, the settlement of nearly one million asylum seekers and refugees since 2015 has sparked violent protest and arson attacks on refugee shelters (Bencek \& Strasheim, 2016). In Austria and Greece, the temporary presence of passing asylum seekers and refugees has fueled the rise of populist right-wing (Steinmayer, 2018) and even neo-fascist (Dinas et al., 2019) parties. In the U.K., areas that witnessed an increase in immigration have been more supportive of Brexit (Becker et al., 2017).

A sizable and fast-growing literature has begun to leverage surveys and natural experiments to examine when migration leads to conflict, and what factors shape natives' attitudes toward migrants. While migration may be forced (i.e. refugees and asylum seekers) or voluntary (i.e. economic immigrants), this research indicates that attitudes toward these groups are highly correlated and share similar foundations (Adida et al., 2019; Bansak et al., 2016; Hangartner et al., 2019). Earlier studies in this field stressed the importance of individual-level economic self-interest and labor market competition in shaping anti-migrant sentiment (Mayda, 2006; Scheve \& Slaughter, 2001), and some have argued that natives in areas and industries with particularly high levels of migration may be more concerned about individual-level labor market competition than natives who are not (Dancygier \& Donnelly, 2013; Malholtra et al., 2017). More recently, however, an emerging consensus has developed that sociotropic concerns related to the economic impact of migrants on host communities (Adida et al., 2019; Bansak et al., 2016; Hainmueller \& Hiscox, 2010; Hainmueller \& Hopkins, 2014, 2015; Valentino et al., 2019) and cultural and religious (i.e. anti-Muslim) concerns about how migration changes local customs and traditions (Adida et al., 2019; Bansak et al., 2016; Card et al., 2005; Hainmueller \& Hopkins, 2014; Hopkins, 2010) are the main drivers of opposition to migration in Europe and the United States. Recent studies suggest that humanitarian considerations may also influence attitudes toward refugees specifically, though 
sociotropic and cultural factors remain the key drivers of attitudes toward these groups (Adida et al., 2019; Bansak et al., 2016).

Our work addresses a limitation in the existing literature. Namely, most of the current evidence on what drives attitudes toward migrants has emerged from studies focused on developed countries, especially in Europe and the United States (e.g. Hainmueller \& Hopkins, 2014; Valentino et al., 2019). And yet, in both aggregate and relative terms, it is developing countries that have been most impacted by the recent wave of migration, which has been driven largely by refugees and asylum seekers fleeing conflicts in Africa, the Middle East, and Asia. Globally, developing countries host 85 percent of the world's 25.4 million refugees and approximately half of the world's 3.1 million asylum seekers. The Middle East and Africa alone host 46 percent of these refugees (UNHCR, 2018). However, we have little evidence for how populations in these countries react to large inflows of migrants and whether our existing theories apply in these contexts. Figure 1 demonstrates this geographic mismatch between the empirical distribution of migrants and refugees and the areas that have been the focus in the academic literature on attitudes toward migrants. For each country, the figure plots the concentration of migrants and refugees against the number of studies in leading political science journals on attitudes toward migrants conducted in that country. There is no apparent relationship between the share of migrants or refugees and the frequency with which a country has been studied. To the contrary, it is precisely the Middle Eastern countries with the largest concentration of migrants and refugees that have received almost no attention in the political science literature on attitudes toward migrants.

We argue that the focus on Western countries in the literature, and the resulting imbalance between where public attitudes toward migrants are studied and where most migration has been occurring, is a limitation of existing academic knowledge on this topic. We lack an understanding of public attitudes toward migration in a range of countries that have been significantly impacted by migration. In addition, our purportedly general theories about the drivers of attitudes toward migrants are built from specific country contexts characterized by relatively high economic and infrastructural capacity to absorb new migrant populations, and relatively high levels of cultural difference between the migrant and host populations. 

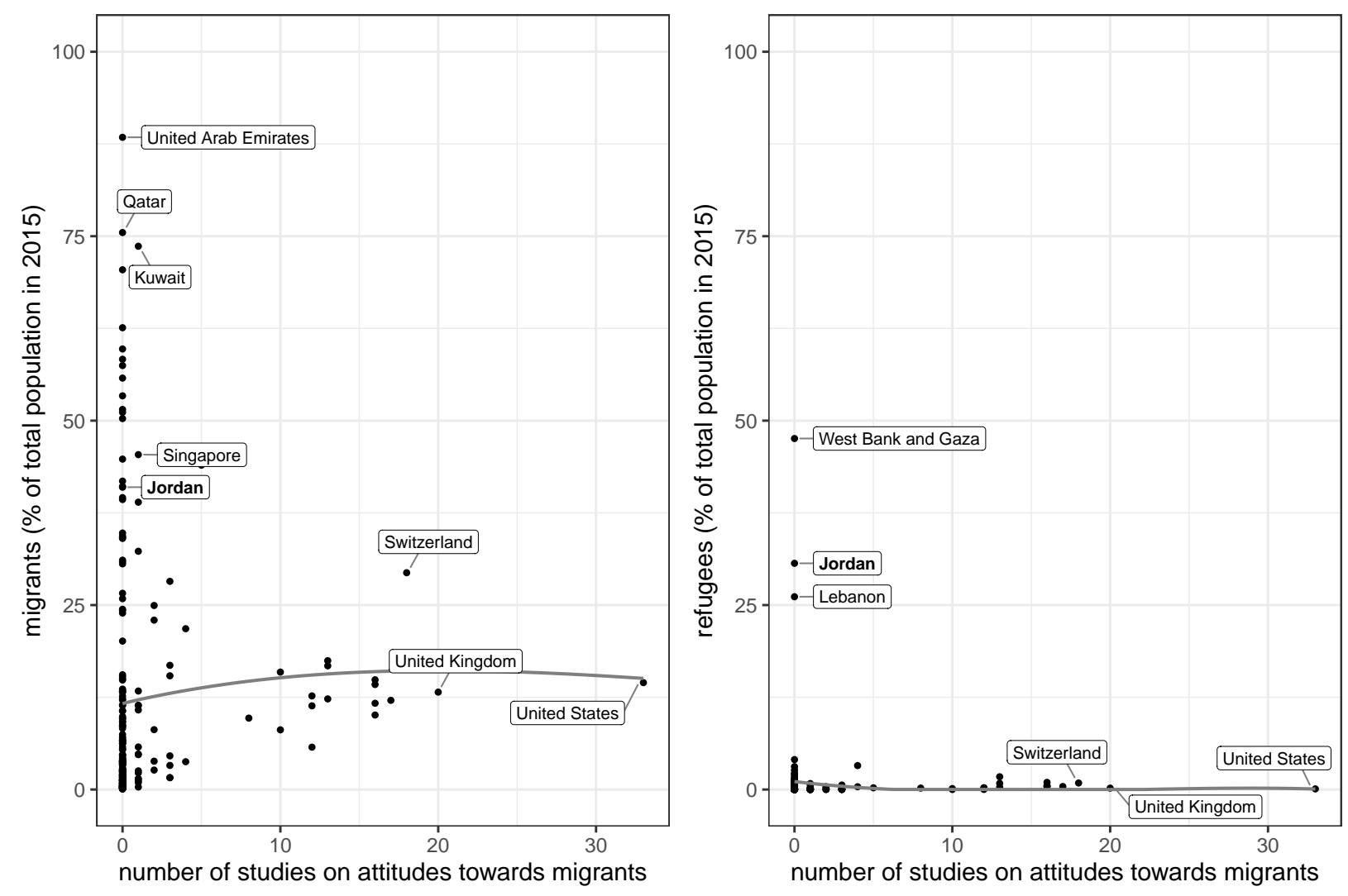

Figure 1: Geographic mismatch between academic literature and concentration of migrants.

Note: Literature count includes studies from the following academic journals between the years 2008 and 2018: APSR, AJPS, JOP, CPS, BJPS, WP, IO, ISQ, JPR, JCR, PSRM, PNAS.

The potential implications of the differences in host country contexts for our theories of attitudes toward migrants are substantial. First, the hypothesis that egocentric economic concerns about labor market competition are a main driver of attitudes toward migrants receives little support in Western countries, where unemployment is low, welfare states are expansive, and, given the language gap, most natives have a baseline higher skill set than new arrivals from abroad. We might expect that this hypothesis could play out very differently in less developed host countries that typically feature limited economic opportunities, weak welfare states, and a higher proportion of migrant arrivals who speak the same language as the native population and have similar skill sets to them.

Second, while sociotropic concerns about the impact of migrants on the economy of host communities are an important driver of attitudes toward migration in developed nations, these concerns 
might be even more prevalent in contexts where immigration further strains typically weak public services, rudimentary education systems, crowded housing markets, and labor markets characterized by high unemployment and general lack of economic opportunities.

Third, several studies (Bansak et al., 2016; Kalkan et al., 2009; Sides \& Gross, 2009) have shown that cultural concerns related to religion, and in particular anti-Muslim bias, are an important determinant of attitudes toward migrants. Given that this concern will not always be shared by the predominantly Muslim societies of the Middle East, where many displaced Muslim refugees have settled in recent years, we might expect that cultural concerns would be less impactful in shaping individuals' attitudes toward migrants than in Western countries.

Despite the importance of less developed countries as test cases for our theories of the drivers of attitude formation toward migrants, limited research has been conducted on this topic in developing contexts to date. To be sure, there exist several insightful qualitative studies about local responses to migration in developing countries (e.g. Adepoju, 2003; Bariagaber, 2006; Frontani et al., 2009; Grabska, 2006; Levitan et al., 2009; Lie, 2019; Martin, 2005; Norman, 2019, 2016; Onoma, 2013), but this literature is not intended to provide a representative survey of mass public opinion or experimental tests of particular drivers of attitudes toward migrants. Researchers interested in testing these questions outside of the Western context face practical challenges to conducting largescale public opinion research in countries where existing survey data or quality sampling frames are often not readily available. In recent years, a handful of scholars have sought to overcome these barriers by conducting quantitative research that addresses attitudes toward migration in developing countries (e.g. Adida, 2011; Buehler \& Han, 2019; Ghosn et al., 2018; Hartman \& Morse, 2018; Zhao, 2018). Although the findings and geographic reach of these studies have been important for expanding our understanding of this issue outside of Western countries, these studies are generally designed to evaluate specific arguments rather than arbitrate between competing theories regarding the factors that shape host populations' attitudes toward migrant communities.

We begin to address these limitations in the literature by conducting a survey of public attitudes toward migration in Jordan, one of the countries most affected by the Syrian refugee crisis that began in 2011. With its weak economy, high rates of unemployment, predominantly Mus- 
lim population, and shared language and overlapping skill set between many Syrian refugees and Jordanian natives, Jordan represents a suitable test case for the generalizability and limitations of theories of attitude formation toward migrants. Using the random walk technique in randomly sampled districts, we fielded a representative survey of 1,500 Jordanians in regions with both high and low concentrations of Syrian refugees. The survey included a combination of observational and experimental research designs. The survey measured attitudes about the perceived impact of Syrian refugees on the country, hostility toward the refugee population, and support for anti-refugee policies, as well as respondent characteristics that have been identified as potential drivers of attitudes toward migrants in other contexts. This data allows us to test which respondent characteristics are important predictors of attitudes toward Syrian refugees. In addition to this observational design, the survey also leveraged a conjoint experiment that asked respondents to choose between randomized profiles of refugees with different attributes, allowing us to test for the relative importance of economic, cultural, and humanitarian considerations in shaping attitudes toward migrants.

In contrast to our theoretical predictions, we find little support for the idea that economic concerns are an important driver of Jordanians' attitudes toward Syrian refugees. Instead, we find evidence that humanitarian and cultural factors have had the most effect on how individual Jordanians perceive the refugee population. Jordanians who have been more economically impacted by the crisis, either personally or in their communities, are no more likely to hold negative attitudes than their counterparts, while Jordanians who are more exposed to refugees' challenging living conditions and who are less sensitive to cultural threat demonstrate more positive attitudes toward refugees. In addition, the conjoint experiment demonstrates that both humanitarian vulnerability and cultural similarity outweigh egocentric and sociotropic economic concerns in determining which Syrian refugees Jordanians prefer to host.

Taken together, these results further undermine egocentric arguments about attitude formation toward migrants, and call into question an emerging consensus around the importance of sociotropic economic factors. On the other hand, in line with existing research focused on Europe (Bansak et al., 2016) and the United States (Newman et al., 2015), our study highlights the potential for humanitarian concerns to sustain public support for hosting migrants over extended periods of time, even in challenging economic circumstances. However, our finding that cultural considerations 
strongly influence Jordanians' willingness to welcome refugees points to a condition on the power of humanitarian concerns. Specifically, most Syrian refugees in Jordan share cultural similarities with their hosts. If these similarities were replaced by salient cultural differences, our findings suggest that Jordanians would be less likely to let humanitarian motives override the perceived economic costs of hosting so many refugees. As a result, our paper reinforces the consensus on the importance of cultural factors in shaping attitudes toward migration.

The remainder of the paper proceeds as follows. We first develop a set of theoretical expectations drawing on the existing literature on attitudes toward migrants, and we then discuss these expectations in the context of the Syrian refugee crisis and its impact on Jordan. Next, we describe our research design, followed by a presentation of our results. We conclude with a discussion of the implications of our findings for the broader literature, as well as practical recommendations for policymakers.

\section{Attitudes Toward Migrant Populations}

The almost exclusive focus on developed countries in the existing literature has made it difficult to assess the strength of empirical support for, and the generalizability of, the four main drivers of attitudes toward migrant populations postulated in existing research.

The first main debate among scholars studying attitudes toward migration revolves around the labor market competition hypothesis. This hypothesis postulates that natives who have a similar skill set as arriving migrants fear that competition for jobs leads to a higher risk of being replaced in the labor force or experiencing downward pressure on wages (Bobo \& Hutchings, 1996; Dustmann \& Preston, 2007; Malholtra et al., 2013; Mayda, 2006; Scheve \& Slaughter, 2001). As a consequence, these natives are particularly opposed to incoming migration. While some studies find support for the labor market competition hypothesis when focusing on native workers in industries most exposed to migration (e.g. Dancygier \& Donnelly, 2013; Malholtra et al., 2017; but see Hainmueller et al., 2015), a survey of the literature reveals that for the general public in Europe and the United States, support for egocentric economic concerns revolving around labor market competition is, at 
best, limited (Hainmueller \& Hopkins, 2014). This result is consistent with the limited impacts of immigration on natives wages in these contexts found in much of the empirical literature (e.g. Dustmann et al., 2012; Foged \& Peri, 2016).

However, this finding of scarce evidence for the labor market competition hypothesis might only hold in the developed contexts studied so far. Developing countries not only host a larger fraction of the world's displaced population, but also feature several other characteristics that make labor market competition between natives and migrants more intense than in developed countries. Unemployment is higher, wages are lower, welfare support offers limited or even no protection against the economic and social consequences of job loss, active labor market programs and retraining opportunities for displaced natives are rare, and the substitutability of migrant and native workers who speak the same language and have similar skill sets is higher. For all of these reasons, we might expect egocentric economic concerns about migration to be more prevalent in developing countries.

The second major theory in the literature posits that sociotropic concerns about the host country's economy, welfare system, and public services shape attitudes toward migrants. An extant literature shows that in the United States and Europe, both high- and low-skilled natives are more welcoming of migrants that are young, educated, skilled, and motivated, and therefore more likely to make a greater economic contribution to the host country economy and less likely to strain welfare systems and public services (Bansak et al., 2016; Citrin et al., 1997; Hainmueller \& Hopkins, 2015). Given that developing countries' economies are weaker, welfare systems are less developed, and public services are more limited than in developed countries, we might also expect sociotropic concerns to be more prevalent in the former.

Third, the existing literature offers a solid consensus that attitudes toward migrants are substantially shaped by perceived cultural threat and concerns that migration will change the host country's dominant culture and identity (Campbell et al., 2006; Card et al., 2012; Chandler \& Tsai, 2001; Golder, 2003; Sinderman et al., 2004). A number of studies show that Americans and Europeans prefer migrants from countries whose cultures are believed to be similar to their own (Dustman \& Preston, 2007; Hainmueller \& Hangartner, 2013; Hainmueller \& Hopkins, 2015). 
Cultural threat also includes religious concerns, and there is a well-documented preference among European and American natives for migrants whose faith traditions match the host country's dominant religion (Adida et al., 2019; Bansak et al., 2016; Kalkan et al., 2009; Sides \& Gross 2009). Bansak et al. (2016) show that in traditionally Christian societies, religious concerns are prevalent in shaping negative attitudes toward Muslim asylum seekers. These cultural preferences are likely rooted in general dispositions toward in-groups and out-groups that individuals develop early in life and deviate from only rarely (Kalkan et al., 2009; Tesler, 2015).

Such cultural and religious concerns may play out differently in developing countries, perhaps even holding less importance overall in determining host community attitudes toward migrant populations. For instance, Adida (2011) suggests that migrants in West Africa who are culturally more similar to host communities face a paradox in which their similarity pushes community leaders to highlight what group differences do exist, thereby increasing barriers to integration compared to migrants who are more culturally distinct. At the same time, since migrants who settle in a developing country often originate from geographically proximate places, their origin and host societies are more likely to share important cultural features. This closeness may decrease concerns among the host population that migration will significantly impact the dominant culture, relative to similar concerns in developed countries addressed by most existing literature. In other words, the smaller cultural distance between refugees and their hosts in most developing countries could translate into a weaker role for cultural concerns in shaping attitudes toward migrants.

Fourth, Newman et al. (2015) suggest that an individual's sensitivity to humanitarian concerns influences their attitudes toward immigration in the United States. Likewise, recent studies including Bansak et al. (2016) and Adida et al. (2019) suggest that attitudes toward asylum seekers and refugees in the United States and Europe are also shaped by humanitarian concerns. For instance, focusing on fifteen European countries, Bansak et al. (2016) show that public preferences are sensitive to humanitarian concerns about the deservingness and legitimacy of the asylum request, as well as the severity of the asylum seeker's vulnerability. In fact, humanitarianism may be particularly salient for attitudes toward refugees, who are legally defined by the need to flee their country due to war, persecution, or violence. As a result, attitudes in developing countries could be driven more heavily by humanitarian concerns than attitudes in developed countries, since refugees often 
make up a higher share of the migrant population in these countries. On the other hand, the large number of refugees in these contexts, combined with the fact that many developing countries have faced repeated waves of refugee arrivals, suggests that humanitarian concerns could be eroded by perceptions that refugees constitute a significant burden.

In sum, we might expect egocentric economic concerns about labor market competition and sociotropic concerns about the host country economy to be stronger, and humanitarian and cultural concerns to be weaker, in developing countries. However, without additional research in these contexts designed to test the relative strength of these theories, it is difficult to know how the factors that underlie attitudes toward migrants compare to those in developed countries. The next section explains the features that make Jordan a good case to test these expectations.

\section{The Syrian Refugee Crisis in Jordan}

To address the sample bias in existing studies of attitude formation toward migrant populations, we focus on the Syrian refugee crisis and its impact on Jordan.

At present, Jordan is one of the world's major hosting countries of Syrian refugees. The Syrian conflict has displaced 13 million Syrians, nearly 60 percent of Syria's pre-conflict population. Nearly half of this number are displaced inside Syria, while approximately 5 million are living in countries that border Syria, including Jordan, Lebanon, Turkey, and Iraq. Figure 2 displays the aggregate numbers of Syrian refugees and their percentage of the total population by host country as of 2017 (Connor, 2018).

As the figure makes clear, the per-capita increase has been particularly significant in Lebanon and Jordan. In Jordan, registered Syrian refugees now constitute seven percent of the total population, and the total percentage is likely much higher given the government's estimates of an additional 600,000 unregistered Syrians residing in the country $!^{1}$ This influx represents a massive and rapid increase in Jordan's population, equivalent to nearly all Canadians moving to the United

$1 \quad$ The government's number is contested. As a result, we rely primarily on the official number of 660,000 refugees registered with UNHCR. 
States as refugees in the span of just a few years. Furthermore, the refugee population demonstrates substantial vulnerabilities: approximately 45 percent are under the age of 15 , while approximately 5 percent are above the age of 60 . Poverty is widespread, even for families in which at least one member is employed (Ajluni \& Lockhart, 2019) ${ }^{2}$

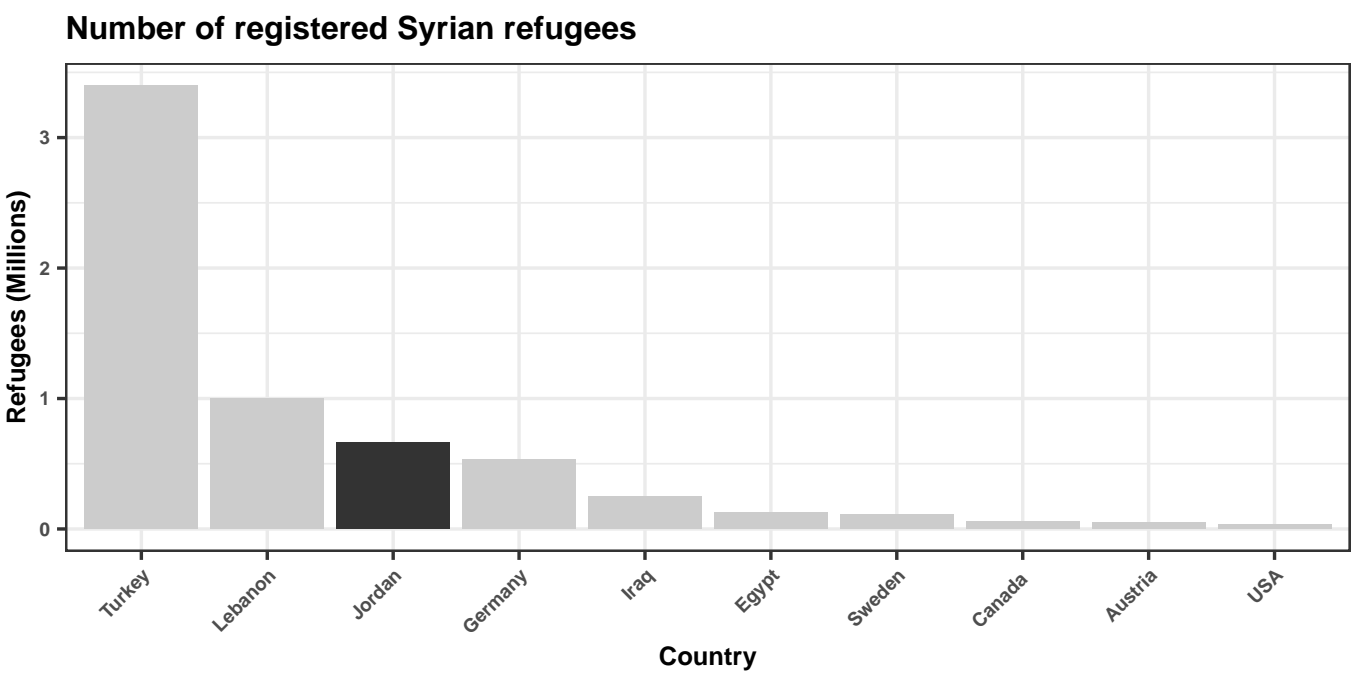

Registered Syrian refugees as percent of population

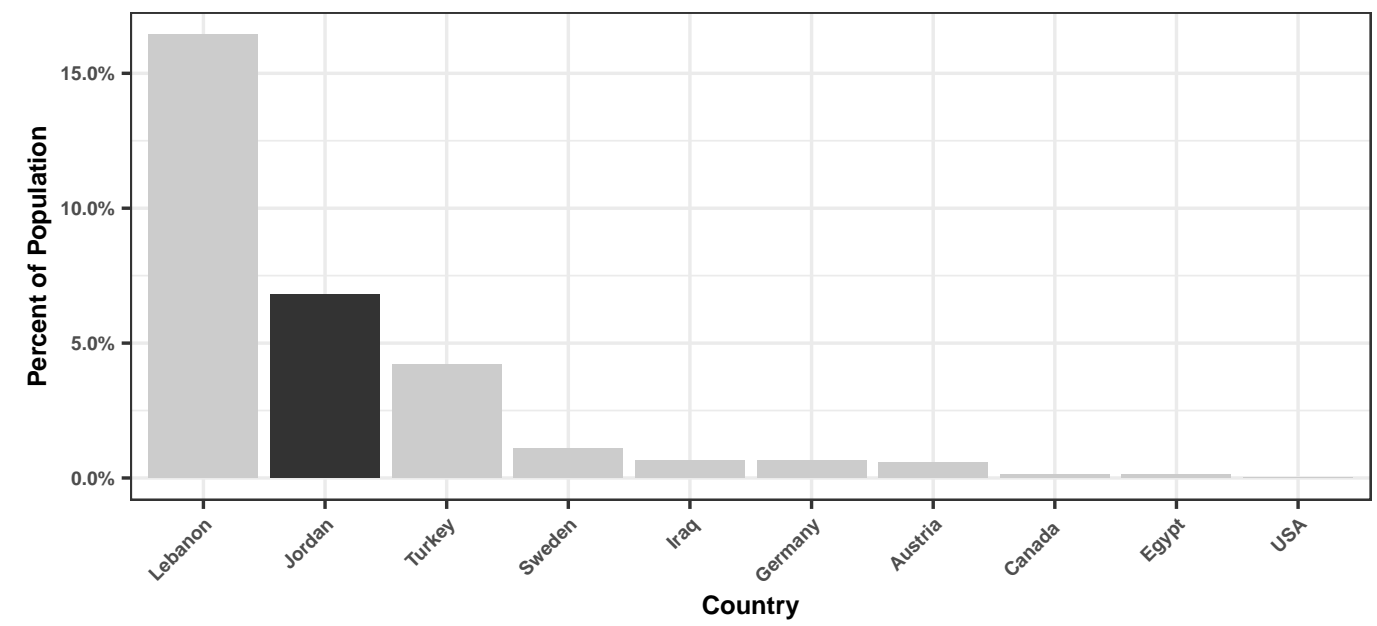

Figure 2: Distribution of Syrian refugees by host country as of 2017

Note: Data in this figure was compiled by the Pew Research Center (Connor, 2018).

Initially, Jordan permitted Syrian refugees to enter the country freely. Many of the earliest arrivals stayed in the north of the country, where they often shared tribal ties with Jordanians (Betts et al., 2017). As the number of refugees increased, UNHCR and the Jordanian government

$2 \quad$ The gender balance among refugees is relatively even, with 51 percent female and 49 percent male (Ajlouni \& Lockhart, 2019). 
opened the Zaatari Refugee Camp in July 2012, which quickly became the fourth largest city in Jordan. Despite government efforts to organize the refugee population, more than 80 percent of Syrian refugees in Jordan have settled outside Zaatari and the other official camps, choosing instead to live in urban areas (Francis, 2015). In the first few years of the crisis, these Syrians were granted access to Jordan's public services, including free medical care and education. However, by 2014, policies became noticeably more restrictive as the number of refugees continued to grow. The government began restricting border crossings with increasing frequency, and shut them down completely following a terrorist attack in June 2016, leaving tens of thousands of displaced Syrians stranded on the Syrian side of the border (Black, 2016; Kayyali, 2017). Refugees' access to free health care in Jordan was revoked in late 2014, and subsidies for health care and bread were lifted in 2018 (Khalidi, 2018; Medecins Sans Frontieres, 2018). The government has also relocated many refugees from urban areas to the camps, while sending some back to Syria (Francis, 2015; Human Rights Watch 2017).

Despite these more restrictive policies related to entry, return, and certain public services, the Jordanian government has increasingly taken steps to integrate Syrians into the labor market and education system. In 2017, the government opened public schools to Syrian children lacking official documents, and the country's schools are estimated to serve more than 100,000 refugees (Al-Abed, 2017). Since the start of the crisis, a significant percentage of working-age Syrians have participated in the economy, often informally in sectors including agriculture, manufacturing, construction, and services. In 2016, as part of a deal with the EU, the government made it easier for Syrians in these sectors to obtain work permits and participate in the labor force legally. As of May 2018, more than 100,000 of these permits had been issued, though uptake was slower than expected and many Syrians continue to work informally (Lockhart \& Dryden, 2018). An August 2017 poll of registered Syrian refugees estimated their labor force participation rate at 55 percent, indicating approximately 200,000 Syrians employed or looking for work (Ajluni \& Lockhart, 2019). Certain high-skilled sectors like medicine and accounting remain closed to formal employment of Syrians, though anecdotal evidence suggests that some do work in these sectors without authorization. For low-skilled Jordanians, it is even clearer that the country's persistently weak labor market combined with the number of Syrians employed or looking for work constitutes a real challenge to their wages 
and employment prospects (Stave \& Hillesund, 2015).

The Jordanian government has defended its halting steps toward integration and its more restrictive border policies by arguing that public opinion makes it difficult to be too favorable to refugees (Francis, 2015). While Jordan's monarchy is an authoritarian regime in which popular input is limited, the government is often responsive to public opinion and does what it can to avoid policies that will trigger unrest. Jordanians vote for and interact frequently with their members of parliament in clientelistic exchanges (Kao, 2015; Lust-Okar, 2006), giving the public direct access to influential members of the political elite who often adopt populist stances. Furthermore, the country has a history of large protests forcing changes to the cabinet and government policies (Ryan, 2018). As a result, though Jordanian politics generally - and attitudes toward refugees specifically - are not tied as closely to partisan organizations and ideologies as in many Western countries, government officials have been wary of perceived disgruntlement among Jordanians about their country's policy toward refugees. In an interview with the authors, officials from a Jordanian government ministry explained that the government was reluctant to provide all Syrians with work permits because of "serious public tension." They felt that even minor changes to such policies could arouse the public's anger and that "the government must be extremely careful about any decision or policy change" as a result. The officials attributed this sensitivity to the fact that "Jordan has been bearing a lot of the costs, [with] huge pressures on health and education," in addition to a public perception that "priority [for aid opportunities] is being given to Syrians."

Although these government claims could be interpreted as an effort to increase pressure on the international community to deliver additional financial assistance to Jordan, there is little doubt that the impact of refugees on Jordan has been substantial and the potential for conflict with host communities is high. Prior to the arrival of Syrian refugees, Jordan's economy was already quite fragile as a result of water scarcity, aging infrastructure, expensive housing, and inadequate job opportunities. In addition, the government has long depended on extensive borrowing to sustain public services and the public sector workforce, which is one of the largest in the world (Malkawi, 2016). These preexisting issues have been exacerbated by the rapid influx of refugees. Between 2011 and 2014, the unemployment rate increased from 14 percent to 22 percent, and from 19 percent to 35 percent for youth aged 15-24. While Jordanians are on average more educated than the Syrian 
refugee population living in Jordan, the ILO estimates that at least some of this increase can be attributed to Jordanians being pushed out of the labor market by refugees (Stave \& Hillesund, 2015). Housing prices increased by as much as 300 percent in 2013 , and the health ministry claimed to be spending half of its annual budget on medical care for Syrians prior to ending free services (Luck, 2013). The government has estimated the annual cost of the crisis to be in the billions (Francis, 2015). Though the international community has provided extensive financial assistance to Jordan, the Jordanian government claims that more assistance is needed to fully cover the costs associated with the crisis (Husseini, 2018).

Given these circumstances, the Jordanian government's concern with hostile public opinion toward refugees is unsurprising. Several European countries experienced a significant public backlash for hosting much smaller refugee populations in both aggregate and per-capita terms, despite having significantly greater resources to absorb them. Extensive anecdotal evidence and some polling data from preceding years suggest that Jordanians have been frustrated with the perceived burdens associated with the hosting of refugees $3^{3}$ These frustrations were clear in focus groups conducted by the authors in January 2017, in which Jordanian participants complained about Syrians stealing jobs, driving up rents, and decreasing the quality of public education. At the same time, incidents of violence between Jordanians and Syrian refugees have been relatively rare, and there has been no political mobilization among the Jordanian public around demands for refugees to be expelled from the country or restricted to camps.

In short, like many developing countries, Jordan is a case in which (1) the number of refugees and asylum seekers is substantial as a share of the national population; (2) refugees and asylum seekers in the country largely share a similar skill set to a portion of the native population; (3) the economy has insufficient capacity to absorb new migrant arrivals; and (4) the government faces severe resource and capacity constraints in trying to deliver services to non-natives, as natives depend heavily on the government for their economic well-being. Existing theories would suggest that Jordan is a context in which egocentric and sociotropic economic concerns should drive attitudes toward migrants, and the burden of hosting migrants should undercut humanitarian considerations. Moreover, as most

$3 \quad$ For example, IRI (2016) found that 61 percent of Jordanians believed that attitudes toward Syrians were getting worse. 
Syrian refugees and native Jordanians share the same language, ethnicity, and religion, cultural concerns should be less relevant as a determinant of public attitudes toward migrants than they are in Western Europe and North America. A study of drivers of attitude formation in the Jordanian context offers us the opportunity to explore the generality of the existing empirical consensus and to identify factors that may condition attitudes in developing countries to a greater degree than in developed contexts.

\section{Research Design}

\subsection{Survey Sample}

To deepen our understanding of attitude formation toward migrant populations in developing countries, we conducted a survey of the Jordanian public in February 2018. The survey was administered by the Center for Strategic Studies at the University of Jordan to a nationally representative sample of 1,200 Jordanians and an additional sample of 300 Jordanians living in areas of high refugee concentration $4^{4}$ Respondents were recruited through a two-stage cluster sampling method, where 150 blocks were randomly selected across Jordan's twelve governorates. Within each block, 8 households were selected using a random walk, providing a sample of 1,2005 In addition, 30 of the blocks were identified as being in the top quintile of refugee density, using data from UNHCR. In these blocks, ten additional respondents were recruited for a sample of 300. CSS relied on the 2015 Jordan census to develop the sampling strategy and create post-stratification weights. The response rate to the survey was $81.8 \%{ }^{6}$ We designed the questionnaire and sampling design with input from two focus groups of young Jordanians, as well as more than 30 interviews with NGOs, international organizations, and Jordanian government officials $7^{7}$

$4 \quad$ The Center for Strategic Studies is a think tank at the University of Jordan that has extensive experience implementing major academic surveys, including the Arab Barometer.

5 To ensure gender parity, half of enumerators recruited only men and half recruited only women, using the birthday method within each household and gender.

6 CSS did not record non-responses for the first 4 days, but started recording them afterwards. The survey ran from February 8, 2018 to March 9, 2018.

7 One focus group was conducted in Amman and one was conducted in Irbid. The focus groups were organized and run by a female Jordanian journalist, with three of the authors in attendance. Discussion focused on perceptions 


\subsection{Study Design}

We leverage both an observational and experimental research design to explore attitudes toward refugees in Jordan.

\subsubsection{Observational Study}

In the observational design, we regress attitudes on respondent characteristics to assesses the most powerful predictors of Jordanians' views of refugees. For outcomes, we measure three concepts: First, we measure perceptions of Syrian refugees by asking respondents how they perceive relations between Jordanians and Syrian refugees, whether they support hosting Syrian refugees, and a feeling thermometer about Syrian refugees. Second, we measure perceptions of the impact of Syrian refugees on Jordan by asking respondents whether the refugees made things better or worse in the following areas: the economy, cultural life, the housing market, the quality of public services, the quality of education, the level of crime, the threat of terrorism, Jordan's image abroad, the agriculture sector, and the overall situation. Third, we measure preferences on a set of refugeerelated policies by asking respondents whether they support four distinct policy measures: closing the border to Syrian refugees, quarantining refugees in camps, sending all Syrian refugees back to Syria, and providing work permits to Syrian refugees. For each of the three categories, we aggregate the questions using principal components analysis to reduce measurement error and use the first principal component as our main outcome of interest. The principal components are normalized to have mean zero and a standard deviation of 1 . The exact wording for all survey questions and details of the principal components analysis are provided in the online appendix.

To capture the drivers of attitudes toward refugees, we measure a large set of respondent characteristics that relate to the different theories of attitude formation toward refugees. We then assess whether respondents with these characteristics demonstrate more negative or positive attitudes toward Syrians as a test of the different theories' relevance to attitude formation in Jordan. Note that these hypotheses were not pre-registered and should be considered exploratory.

of and attitudes toward refugees. Recruits were Jordanian youths from diverse backgrounds, with a mix of women and men. 
To identify respondents who should be more sensitive to egocentric economic concerns, we measure income, education, and age. If egocentric economic concerns are an important driver of Jordanians' views toward refugees, we expect Jordanians with lower incomes and education levels, as well as those who are younger, to exhibit higher levels of anti-refugee sentiment. As alluded to previously, the majority of Syrians in Jordan work in low-paying occupations in the informal sector, including as barbers, waiters, and agricultural and construction workers. Even those Syrians who have obtained official work permits are relegated to these sectors in an effort to reduce competition for more prestigious and higher-paying fields. As a result, lower-income, less-educated, and younger Jordanians are more likely to be excluded from the workforce, or to experience downward pressure on their wages, as a result of the refugee crisis (Stave \& Hillesund, 2015). In addition, if egocentric economic concerns are an important driver, we also expect Jordanians of Palestinian (West Bank) descent, who make up a significant percentage of the population, to hold more negative perceptions of the Syrian refugee population. This is because Jordanians of Palestinian descent tend to work in the private sector, compared to Jordanians of East Bank descent who are more likely, on average, to be employed by the government (Ryan, 2010). As a result, Jordanians of Palestinian descent should be more exposed to economic competition with Syrian refugees. To measure West Bank identity, we ask respondents which city their family is originally from and then we code this city as part of the East or West Bank.

To capture exposure to sociotropic economic concerns at the community level within Jordan, we measure geographic proximity to refugees based on the expectation that areas with large numbers of refugees will be more sensitive to increased pressure on local public services like schools and water, as well as rising rent prices (Zhao, 2018) ${ }^{8}$ If sociotropic economic concerns are an important driver of Jordanians' views toward refugees, we would therefore expect that respondents who reside in areas with greater concentrations of refugees will express more negative perceptions of the Syrian population. We measure proximity by asking about the frequency of contact with Syrian refugees and using localized data on the density of refugees.

$8 \quad$ While greater humanitarian aid in these areas might offset these costs somewhat, the Jordanian government claims that aid has not been enough to match the country's needs (Husseini, 2018). As a result, it is likely that communities with more refugees have faced higher pressure on the local economy because of the crisis. 
To capture intensity of cultural concerns, we code an index based on a battery of questions asking respondents to indicate their tolerance of people from religious groups different than their own. Specifically, respondents are asked about the extent of their concern that people from other religious groups have different values and cultural practices than their own, are unappealing as potential marriage partners, or contribute negatively to Jordan's cultural and social diversity. Respondents who score high on this index should be more sensitive to cultural threats, since it captures their negativity toward out-group members across a salient cultural divide. Of course, culture is inherently multidimensional, and religion is only one aspect of Jordanian culture; nonetheless, it is an important one, and attitudes toward religious out-groups likely speak to more general antipathy toward deviations from the country's dominant culture 9 As a result, if cultural concerns are an important driver of attitudes toward refugees in the Jordanian context, we expect that individuals with higher scores on the index will hold more hostile perceptions of Syrian refugees.

Finally, we use three measures to capture sensitivity to humanitarian concerns. First, we measure respondents' religiosity by asking about the frequency of attending services at a mosque or church. Albeit an imperfect measure, scholars have shown that religiosity relates to sensitivity toward humanitarian need (Malka et al., 2011; Steenbergen, 2004). If humanitarian concerns are an important driver of Jordanians' attitudes, we expect that greater religiosity will correlate with more positive perceptions of Syrian refugees. Second, Jordanians who have more frequent contact with Syrian refugees may also be more attuned to their daily struggles, and therefore better able to empathize with their humanitarian plight (Ghosn et al., 2019). We therefore expect that contact will be associated with more positive perceptions of the refugee population if humanitarian concerns are an important driver of Jordanians' attitudes toward Syrian refugees. As mentioned above, we measure contact through self-reporting and with data on the size of local refugee populations. Third, research suggests that women are more attuned to humanitarianism (Steenbergen, 2004); as a result, we expect that women will demonstrate more favorable attitudes toward refugees if

$9 \quad$ The overwhelming majority of Jordanians claim that religion is important in their lives and that they engage in religious practices regularly (Williamson, 2019). The importance of religion in Jordanian culture is reinforced by the state, which since its founding has regulated a large religious establishment including thousands of preachers, mosques, charities, and other organizations. It is also reinforced by the regime, which seeks to promote its own vision of Jordanian Islam (Robbins \& Rubin, 2013). 
humanitarian concerns have contributed to the host population's views on refugees.

Our core models also control for respondents' general political knowledge and household size. In addition, we control for exposure to one of three experimental treatments for a vignette experiment whose results are reported elsewhere. Standard errors are clustered at the district level ${ }^{10}$

\subsubsection{Conjoint Experiment}

In addition to the exploratory observational design, we implemented a randomized conjoint experiment (Hainmueller et al., 2014) to identify the effects of refugees' specific attributes on Jordanians' willingness to host them. Hypotheses for the experiment were pre-registered with EGAP in December 2017, prior to the implementation of the survey 11

For the conjoint experiment, respondents were asked to compare pairs of hypothetical Syrian refugee profiles. Each profile consisted of the following nine attributes: gender, age, occupation in Syria, economic situation, current place of residence, education level, religious sect, reason for fleeing Syria, and family status. The various levels associated with these attributes can be viewed in Table 1, along with the instructions and questions accompanying the profiles. The levels were fully randomized with the exception of two restrictions, intended to avoid particularly unrealistic or confusing combinations: we did not allow the profiles to include a refugee who was 62 -years old and widowed with children, or a refugee with less than a university education who was an accountant or engineer.

After viewing the profiles, respondents were first asked to rate each profile on a scale of 1 to 7 regarding whether Jordan should host the refugees and second to select which of the two profiles they preferred Jordan to host. We pre-specified the latter forced choice as our primary outcome, but results for the rating outcome are similar. Overall each respondent was asked to rate five pairs yielding a total sample for the conjoint analysis of 15,000 refugee profiles. The order of the attributes was randomized across respondents, but fixed across tasks for the same respondent.

$\overline{10}$ Jordan is divided into twelve governorates, and these governorates are divided into 51 districts known as liwa. We clustered standard errors at this level.

11 Registration ID: 20180110AB. 


\begin{tabular}{|c|c|}
\hline Attributes & Values \\
\hline \multirow[t]{2}{*}{ Gender } & Male \\
\hline & Female \\
\hline \multirow[t]{3}{*}{ Age } & 21 \\
\hline & 38 \\
\hline & 62 \\
\hline \multirow[t]{5}{*}{ Occupation in Syria } & Unemployed \\
\hline & Farmer \\
\hline & Barber \\
\hline & Accountant \\
\hline & Engineer \\
\hline \multirow[t]{3}{*}{ Economic Situation } & Relies on UNHCR benefits \\
\hline & Relies on Jordanian charities \\
\hline & Self-Sufficient \\
\hline \multirow{2}{*}{ Current Place of Residence } & Zaatari Camp \\
\hline & Irbid \\
\hline \multirow[t]{4}{*}{ Education Level } & Primary \\
\hline & Secondary \\
\hline & Vocational \\
\hline & University \\
\hline \multirow[t]{3}{*}{ Religious Sect } & Sunni \\
\hline & Orthodox Christian \\
\hline & Alawite \\
\hline \multirow[t]{4}{*}{ Reason for Fleeing } & Political Persecution \\
\hline & Lack of Job Opportunities \\
\hline & Abandoned unit after fighting in the Syrian war \\
\hline & Violence Near Home \\
\hline \multirow[t]{4}{*}{ Family Status } & Single \\
\hline & Married without Children \\
\hline & Widowed without children \\
\hline & Widowed with children \\
\hline
\end{tabular}

Table 1: Attributes for the Conjoint Profiles of Syrian Refugees

The attributes defined for each refugee profile were designed to capture various theoretical predictions, and we conducted focus groups after the survey to validate that Jordanians' perceptions of the attributes aligned with our use of them. First, if attitudes are driven by egocentric concerns about job competition and personal economic interest, we expect that respondents should prefer refugee profiles that do not share their own level of professional skill or education, as well as profiles that are further from their own age (Hainmueller \& Hopkins, 2015). In addition, respondents should prefer refugees living in Zaatari refugee camp, which is removed from areas of active labor market activity, and they should penalize refugees coming from Syria primarily for greater job opportunities.

Second, if sociotropic economic concerns shape attitudes toward refugees in Jordan, respondents should prefer refugee profiles with higher levels of education and more skilled employment, since 
these refugees should be more likely to contribute to the economy (Hainmueller \& Hopkins, 2015). Furthermore, respondents should prefer refugees with the resources to be self-sufficient, rather than those relying on public assistance.

Third, to test the influence of cultural concerns on Jordanians' attitudes toward the refugee population, we again turn to religion as one salient marker of cultural identity and threat (Bennet, 1988; Campbell, 2006; Dunn et al., 2007; Kalkan et al., 2009). Refugee profiles were randomly assigned to be Sunni Muslim, Alawite Muslim, or Orthodox Christian. Note that Sunni Muslims are predominant in Jordan, but just under ten percent of the population is Christian. Alawite Muslims constitute a sect usually associated with Shiite Islam that is prominent in Syria. Most Syrian refugees in Jordan are Sunni, and the numbers of Christian and Alawite refugees are very small in comparison 12 Nonetheless, if cultural threat is a concern that shapes attitudes toward refugees, we would expect respondents to prefer Sunni Muslim profiles to Alawite and Christian profiles because of their alignment with the country's dominant religious identity.

Fourth, if humanitarian concerns contribute significantly to Jordanians' attitudes surrounding which refugees to host, respondents should prefer profiles that demonstrate heightened vulnerabilities to conflict, including profiles that are identified as females, widows, the elderly, those with children, and those dependent on UNHCR or Jordanian charities. While these attributes may not be associated with perceived vulnerability in all circumstances, they reflect closely the characteristics that international organizations and advocacy groups use to define vulnerability in migration contexts (Hruschka \& Leboeuf, 2019). For instance, the UNHCR Resettlement Handbook (2011) discusses six vulnerable groups exposed to greater risk of harm as a result of migration, of which the first three are "women and girls," "children and adolescents," and "older refugees." This emphasis occurs in other UNHCR sources as well (UNHCR, 2015, 2017). More generally, public opinion in various contexts often appears to view women, children, and the elderly as groups deserving of special protections (e.g. Eastmond \& Ascher, 2011; Frey et al., 2010; Silverstein \& Parrott, 1997). In addition, to the extent that humanitarian concerns shape attitudes, respondents should prioritize

12 As of 2014, an estimated 20,000 Syrian Christians had entered Jordan (Glatz, 2014). The number of Alawite refugees is likely minuscule, in part because Alawites have been more closely tied to the Assad regime and less likely to flee Syria as a result. 
Syrians who have a legitimate claim to refugee status - i.e. those fleeing persecution and violence, as opposed to Syrians escaping a lack of job opportunities or abandoning their unit after fighting in the war.

Table 2 provides an overview of the hypotheses for both the observational analysis and the conjoint experiment. The table also outlines our earlier discussion of existing findings on attitudes toward migrants in Western contexts, as well as our broader expectations about the role of economic, cultural, and humanitarian concerns in the Jordanian context. 


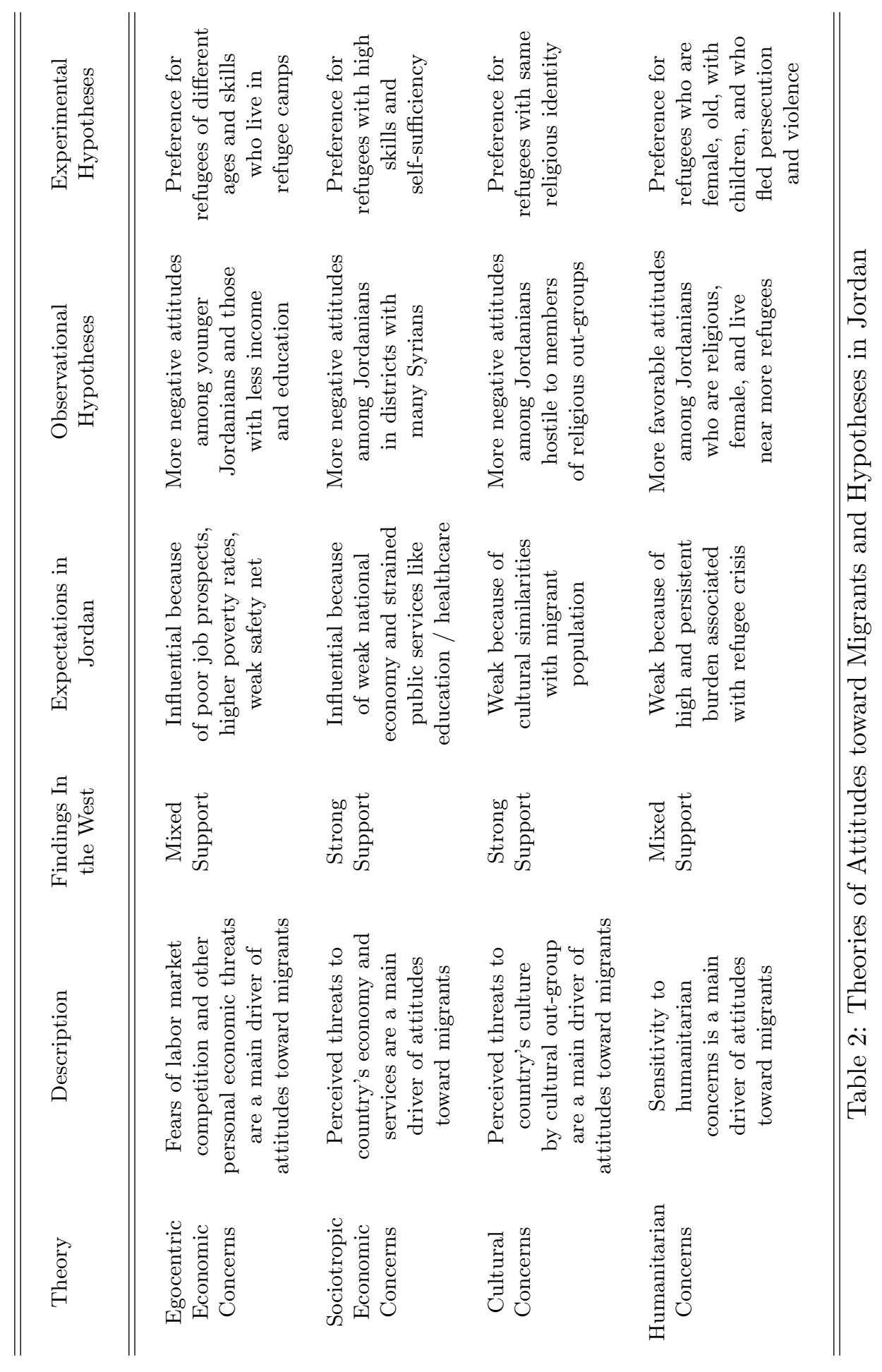




\section{Results}

\subsection{Results of Observational Study}

Figure 3 shows the estimated marginal effects from the regressions of the three measures of perceptions of Syrian refugees on the respondent characteristics ${ }^{13}$ Positive coefficients indicate more positive attitudes, less negative perceptions of impact, and stronger pro-refugee policy positions. The findings support hypotheses about the role of humanitarianism and cultural threat in shaping attitudes, and they provide almost no support for hypotheses about the role of egocentric or sociotropic economic threat.

Regarding egocentric economic concerns, income shows no consistent relationship with the three outcome variables. And when there is a significant relationship, the effect size is small. Younger Jordanians, who should be more likely to experience economic competition with Syrians, are if anything more positively inclined toward the refugee population (younger people are slightly more positive about the impact of refugees). Likewise, Jordanians of West Bank origin are more likely to hold positive views on all three outcome measures. This pattern runs contrary to our expectations about the importance of egocentric economic threat, since West Bank Jordanians are less likely to be employed by the government and should be more exposed to economic competition with Syrians. Only the education variable aligns with our hypothesis in favor of the egocentric economic threat argument, as higher educational attainment is weakly correlated with more positive views of refugees. A one-level increase in education, such as from completing high school to completing university, is associated with up to 0.09 standard deviation $(95 \%$ C.I. $=0.03-0.14)$ increase in the attitudes measure, representing less than one-tenth of a standard deviation. This finding might also be attributable to higher levels of tolerance among more educated respondents (Hainmueller \& Hopkins, 2014).

Hypotheses related to the importance of sociotropic economic threat in shaping attitudes also find little support. The measures of contact intended to proxy for sociotropic impact do not indicate that greater pressure on one's community as a result of the refugee crisis is associated with

\footnotetext{
13 Figure A.1 in the online appendix shows the results using an additive index for each outcome.
} 


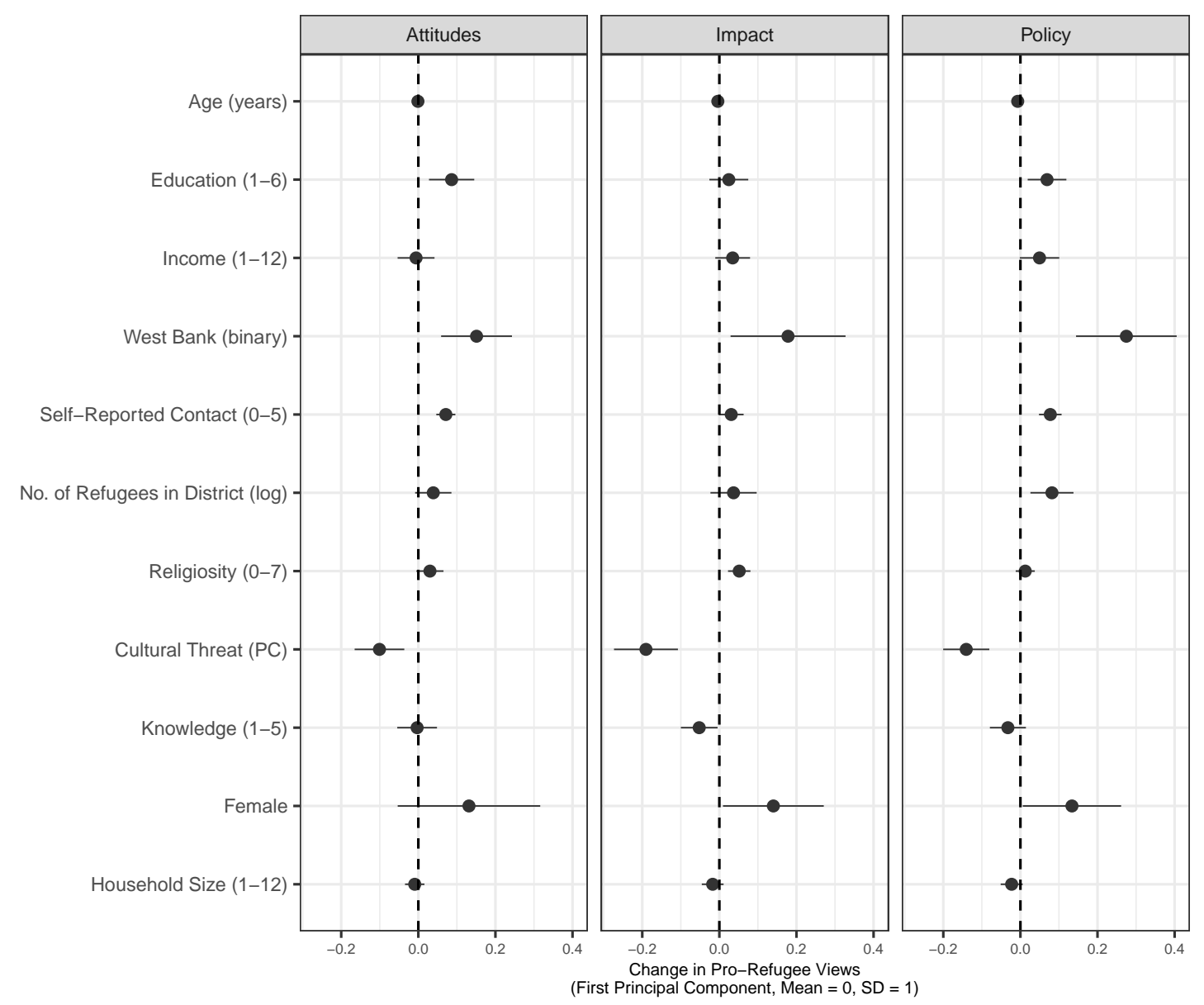

Figure 3: Relationship between respondent characteristics and views of refugees.

Note: Coefficient plots from a multiple regression of the first principal components of the attitudes, impact, and policy outcomes on the respondent characteristics. Regressions also controls for exposure to one of three experimental treatments for a vignette experiment (not reported here). 
more negative attitudes toward refugees. If anything, these proxy measures are correlated with more positive views of Syrian refugees. More frequent self-reported contact is associated with more positive attitudes and policy positions, and higher numbers of refugees in the respondents' district is also associated with greater support for pro-refugee policies. These patterns are consistent instead with our hypotheses about the importance of humanitarian concerns. Also consistent with the relevance of humanitarianism, greater religiosity is weakly correlated with more positive attitudes and less negative impact assessments, and women are less likely to perceive the impact of refugees as negative, and more likely to oppose policies that would harm refugees.

Finally, a higher score on the cultural threat index-indicating greater sensitivity to differences between oneself and other religious groups - is strongly correlated with negativity toward the refugee population on all three outcome measures. This finding suggests that, in spite of the relative similarity between the host and refugee communities in Jordan, cultural concerns remain an important factor in shaping Jordanians' attitudes toward Syrian refugees. An increase in the cultural threat index by one standard deviations is associated with as much as -0.19 standard deviation $(95 \%$ C.I. $=-0.27-0.11)$ change in the outcome measures.

\subsection{Results of Conjoint Experiment}

We follow the standard approach for analyzing randomized conjoint experiments, using OLS regressions with standard errors clustered by respondent to estimate the Average Marginal Component Effect (AMCE) for each attribute. Note that the AMCE represents the marginal effect of an attribute averaged over the joint distribution of the remaining attributes (Hainmueller et al., 2014). Figure 4 displays the AMCE for the forced choice and the rating outcomes. Each dot represents the AMCE on the probability that respondents chose to host the Syrian refugee in Jordan; the unfilled circles are the reference categories and the horizontal lines are robust $95 \%$ confidence intervals.

The results from the conjoint experiment are consistent with the observational analysis in showing that humanitarian and cultural concerns, rather than egocentric or sociotropic economic threats, play the strongest role in shaping attitudes toward the refugee community in Jordan. Religious sect had by far the largest impact on respondents' preferences: In the forced choice 

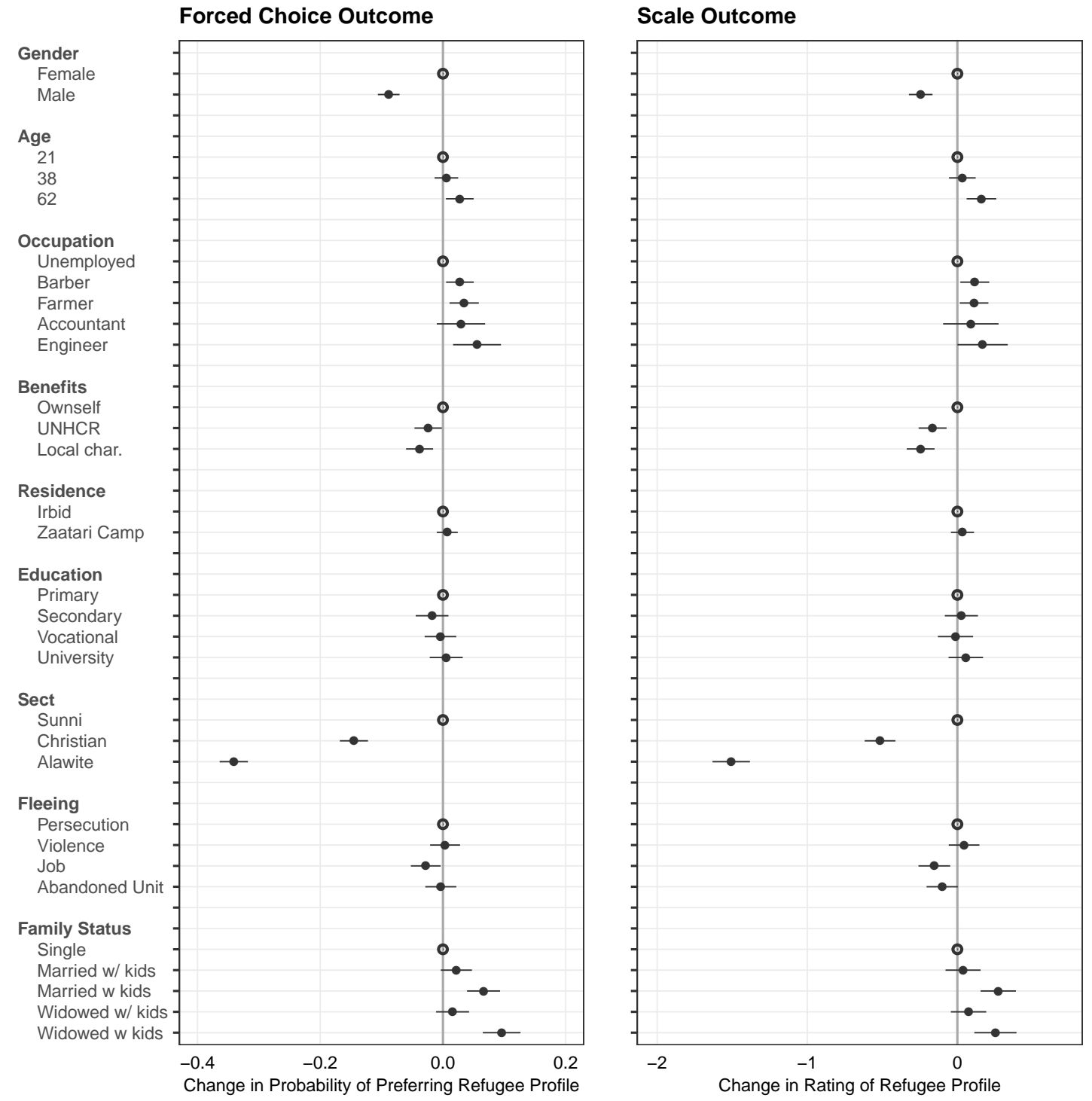

Figure 4: Main results from the conjoint experiment. 
outcome, Alawite Muslims were 34 percentage points $(95 \%$ C.I. $=0.32-0.36)$ and Christians were 15 percentage points $(95 \%$ C.I. $=0.12-0.17)$ less likely to be preferred by respondents compared to Sunni refugees. The next largest effects were for men, who were penalized by 9 percentage points $(95 \%$ C.I. $=0.07-0.11)$ as compared to women, and for families with children, who were 10 percentage points $(95 \%$ C.I. $=0.06-0.13)$ more likely to have been chosen when the parent was widowed and 7 percentage points $(95 \%$ C.I. $=0.04-0.09)$ more likely to be chosen when the parent was still married.

Engineers received a boost of 5 percentage points $(95 \%$ C.I. $=0.02-0.10)$ as compared to the unemployed, while barbers 3 percentage points $(95 \%$ C.I. $=0.00-0.05)$ and farmers were 4 percentage points $(95 \%$ C.I. $=0.01-0.06)$ more likely to be chosen, respectively. The oldest refugee profiles were 3 percentage points $(95 \%$ C.I. $=0.00-0.05)$ more likely to be selected, and refugees said to be fleeing Syria for job opportunities were 3 percentage points (95\% C.I. $=0.00-0.05)$ less likely to have been selected. Finally, refugees relying on UNHCR benefits were penalized by 2 percentage points $(95 \%$ C.I. $=0.00-0.05)$ and those receiving benefits by Jordanian charities were penalized by 4 percentage points $(95 \%$ C.I. $=0.02-0.06)$ percentage points. Other attribute levels were statistically insignificant. The results from the rating outcome are substantively similar to those from the forced choice outcome.

Interaction terms provide little support for the hypothesis that egocentric economic concerns play a significant role in shaping Jordanians' attitudes toward the refugee population. Figure 5 and Figure 6 present evidence that the AMCEs do not differ for respondents who are more likely to be in competition for jobs with refugees, including those who are unemployed and those with less than college education. Neither of these groups are noticeably more likely to select refugees with skill levels and vocations that would present less as compared to more job competition. In addition, the AMCEs also do not differ noticeably by respondent age ${ }^{14}$ Furthermore, the main effects also provide little support for the importance of egocentric concerns. While the significant negative effect for the job level is consistent with this hypothesis, the non-effect on Zaatari camp is not.

$14 \quad$ See Figure A.7 in the appendix. 
The results provide only weak support for the hypothesis that sociotropic economic concerns shape Jordanians' attitudes toward refugees, particularly when compared to stronger findings in the literature from Western countries. The fact that respondents prefer self-reliant refugees provides some support for this hypothesis, as does the fact that engineers, barbers, and farmers received a statistically significant advantage over Syrians who had been unemployed prior to arriving in Jordan. However, these effect sizes are relatively small, and it is notable that neither engineers nor accountants are more likely to be selected by respondents than refugees coming from lower-skilled occupations. Furthermore, the refugee's education level had no effect on Jordanians' preferences. These education null effects contrast with several previous studies in the United States and Europe showing that migrants with higher levels of education are preferred by host community members (Bansak et al., 2016; Hainmueller \& Hiscox, 2010).

The particularly sizable effects for the religious attributes provide support for the hypothesis that Jordanians are wary of potential cultural differences with refugees arriving to the country, and that they are much less likely to welcome those refugees who appear to fall outside the country's cultural mainstream. The vast majority of Syrian refugees in Jordan are Sunni, and the negative effects for Alawites and Christians provide strong evidence that the Jordanian public considers this alignment with the host culture to be important. To bolster this interpretation, we also divided our sample into more and less religious respondents, and examined subgroup effects for the religious attributes among these two groups. In both cases, the penalty for Alawite and Christian Syrians is substantively similar, suggesting that religious identity serves as an important marker of Jordanian culture even among non-religious Sunni Jordanians. This hostility to cultural differences aligns with other research from Western contexts indicating that prejudice and xenophobia toward perceived out-groups often underlies opposition to migration (Dustmann \& Preston, 2007; Sniderman et al., 2004).

The results also provide evidence for the importance of humanitarian concerns. Following religious identity, gender and children demonstrate the next largest effect sizes, which suggests that respondents prioritize hosting the most vulnerable refugees. This finding is in line with similar results derived from European populations (Bansak et al., 2016). Age also produced a statistically significant effect, with elderly refugees being more likely to be selected. Furthermore, while refugees 
fleeing persecution and violence were not more likely to be selected than refugees abandoning their unit in the civil war, they were more likely to be selected than refugees fleeing for better employment opportunities ${ }^{15}$ Only the benefits attribute did not offer support for the humanitarian hypothesis, since respondents were more likely to select self-reliant refugees over those dependent on UNHCR or local charities 16

\subsubsection{Evidence from Focus Groups}

One potential issue with the experimental design is that respondents may interpret the attributes differently than the researchers. For instance, the strongly negative Alawite effect may reflect dislike of the Assad regime in Syria rather than concerns about cultural differences with Jordanians. To assess the extent to which respondents' interpretations aligned with our hypotheses, we conducted two focus groups with new groups of Jordanians following the implementation of the survey, one in May 2018 and another in July 2018. As part of the focus group, participants answered the same conjoint questions individually and discussed their reasons for doing so with the group. The discussions were managed by a female Jordanian facilitator with previous experience conducting focus groups. The focus groups were arranged by the Center for Strategic Studies at the University of Jordan and hosted by local charities in two lower/middle class neighborhoods of Amman. ${ }^{17}$

In both focus groups, participants' interpretations of the categories generally reflected the researchers' understanding. Regarding age, gender, and family status, humanitarian concerns

15 While refugees who abandoned their unit may not be clearly deserving of refugee status, it remains the case that they were described as fleeing from violence, which may explain the lack of an effect relative to the "political persecution" and "violence near home" values.

16 It should be noted, however, that many Jordanians believe refugees who receive benefits also work and sometimes sell the benefits, and so these refugees may in fact be perceived to be better off. As a result, this attribute is not our most effective test of the humanitarian hypothesis.

17 Respondents were recruited by the charities through their contacts in the community. They were paid a small incentive for their participation and transportation costs. The first focus group included 8 women and 4 men. The women included a mix of students, housewives, and others, while employment for the men ranged from a taxi driver to a government employee in the Jordan Monetary Authority. The second focus group included 8 women and 3 men. The women included a mix of teachers and housewives, and the men included two engineers and a student. 


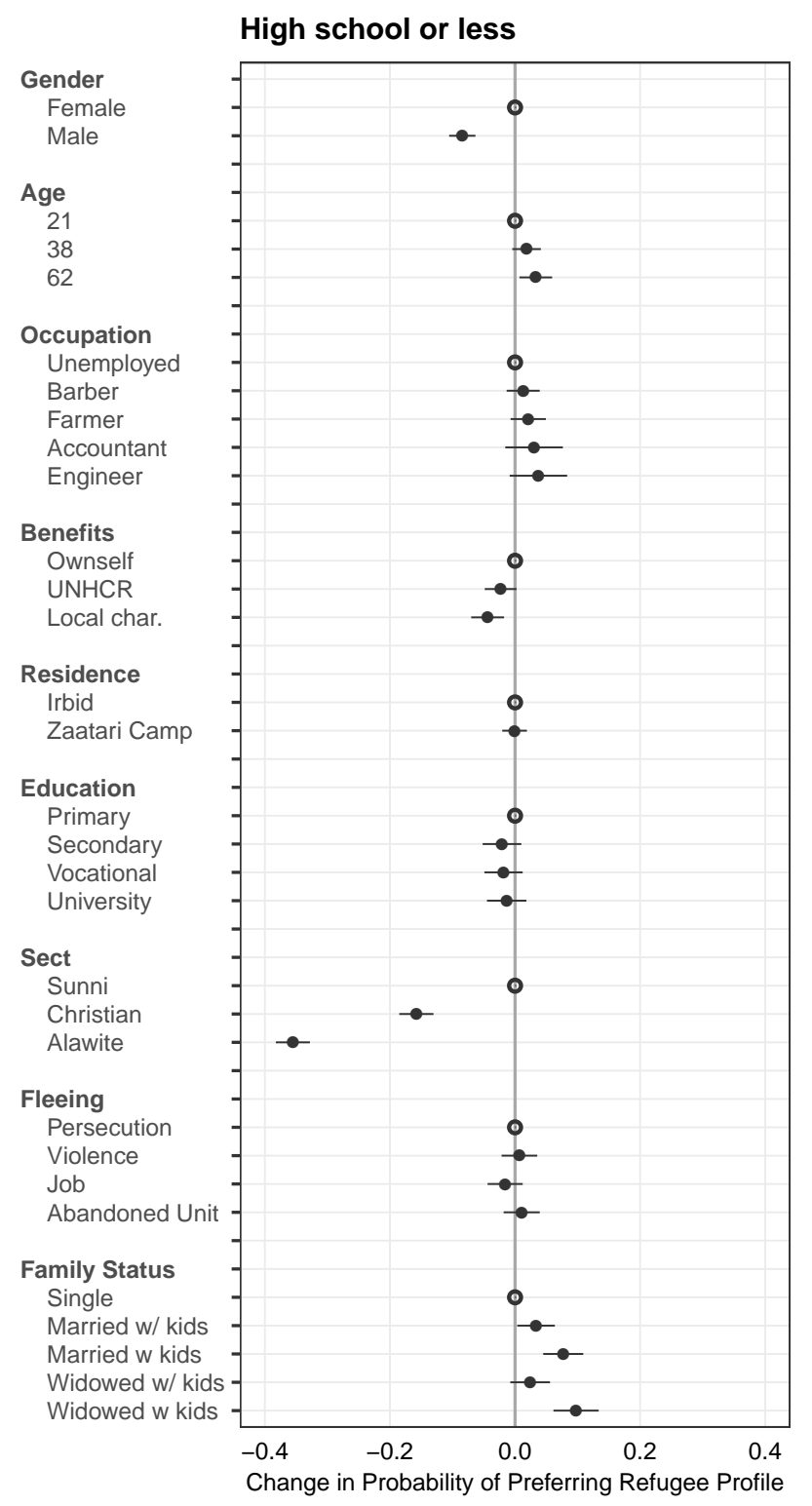

More than high school

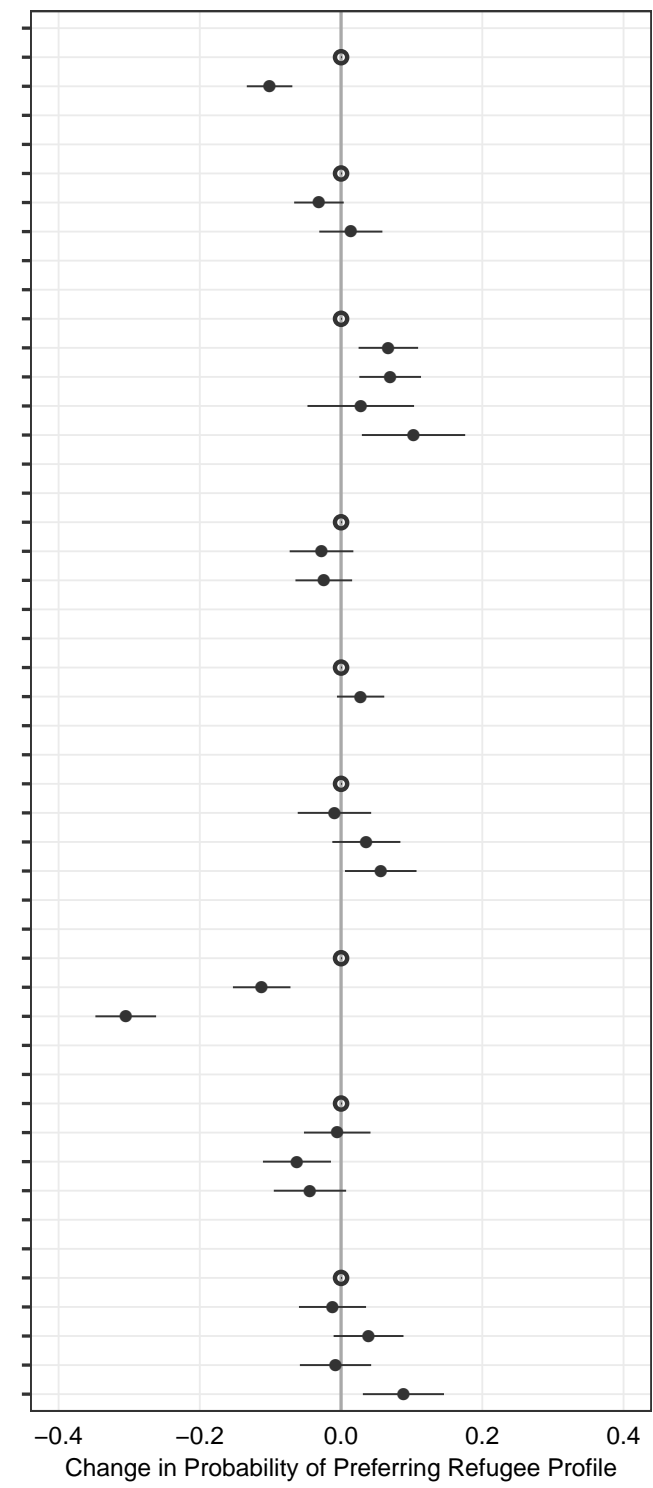

Figure 5: Conjoint results by respondent education. 


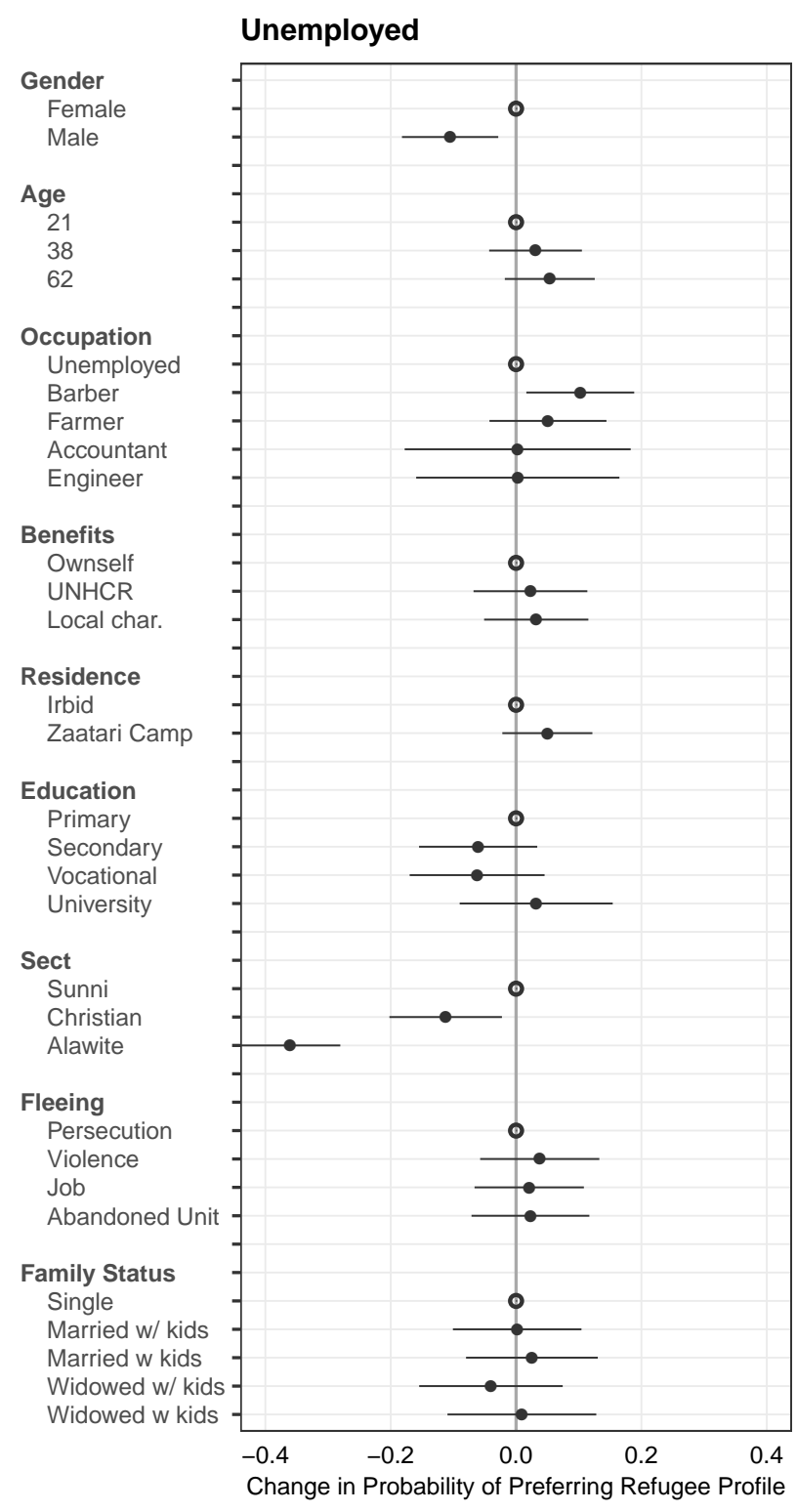

\section{Employed}

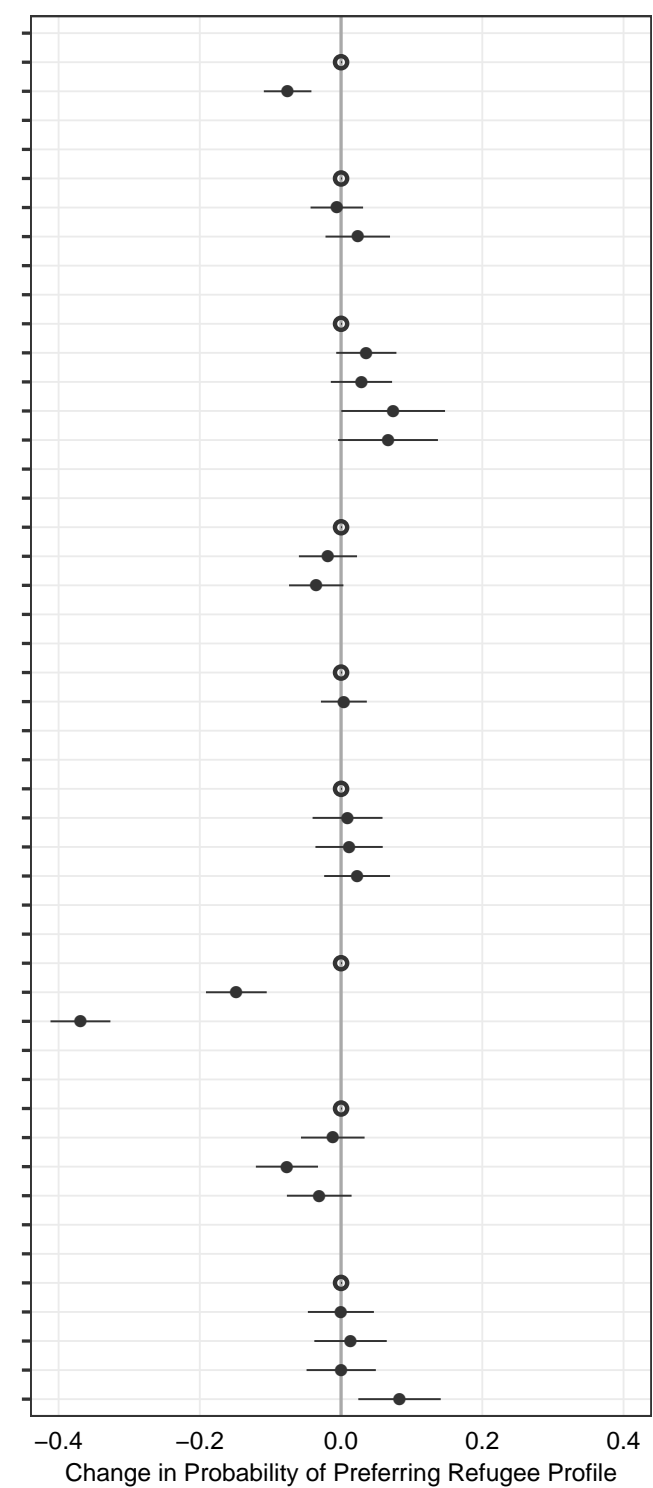

Figure 6: Conjoint results by respondent employment status. 
were predominant. One participant said she preferred to host females because "they are the most...exposed to violence" (Female 1 in Focus Group 1, 2018) while another preferred to host older refugees because "it is difficult for the elderly to stay in [Syria]" (Female 4 in Focus Group 1, 2018). Several participants appeared to prioritize refugees who had children, explaining that children have "the right to live" (Female 3 in Focus Group 1, 2018) and are "innocent...from a humanitarian perspective" (Male 2 in Focus Group 1, 2018). Another noted that "kids don't have people to look after them" (Female 7 in Focus Group 2, 2018) and one simply stated "humanity" when asked why they favored children and widows (Female 4 in Focus Group 2, 2018). When participants were later shown the survey results and asked to explain why family considerations mattered in the conjoint, they emphasized "the emotions of the Jordanians" (Male 6 in Focus Group 1, 2018) and "Jordanian magnanimity" (Male 1 in Focus Group 1, 2018).

Participants who brought up religious sect expressed concerns about bringing new sects into the country, particularly Alawites, due to the potential for unwanted cultural transmission. As stated by one participant, "Jordan has only two religions, [Sunni Islam and Christianity], so there is no need to bring in any other doctrines" (Male 3 in Focus Group 1, 2018). Participants worried explicitly about Alawites influencing the ideas of Jordanian children, noting that they "may influence our kids'...beliefs when they are mixed with them" (Female 4 in Focus Group 2, 2018) and that they "have thoughts they may spread, kids can absorb any idea" (Male 2 in Focus Group 2, 2018). One participant described a situation in which her daughter had allegedly become confused about how to pray because of interactions with an Alawite Syrian refugee at school (Female 3 in Focus Group 2, 2018). This woman held the view that "everyone" in Jordan shares her dislike of Alawites "for the very simple reason that they don't share the same religion as we do."

On the other hand, Christians were viewed as less culturally distinct from the Sunni majority. One participant stated that Christians are "a bit better than the Alawite" because, "there's only a slight difference between Muslims and Christians" (Female 2 in Focus Group 2, 2018). Another participant emphasized that "we live with Christians and they are just fine" (Female 4 in Focus Group 2, 2018). This difference, according to one participant, occurs because "Christians are people of the book [like Sunni Muslims], but the Alawite is a Shiite" (Male 3 in Focus Group 2, 2018). This same participant went on to express negative views of how Alawites were transmitting 
dangerous cultural practices and beliefs, claiming that Alawites "brought temporary marriage [and] persecuted women. They have totally different religious concepts than we do, a different Quran, different prophets" (Male 3 in Focus Group 2, 2018) 18

When education was mentioned, it typically reflected sociotropic economic concerns, as when one participant said he preferred more highly educated individuals "to cover the country's economic and academic needs" (Male 4 in Focus Group 1, 2018). Another participant stated that "an illiterate person whom I have to feed and educate...becomes a burden," whereas, "when he's educated, he can go to any job" (Female 7 in Focus Group 2, 2018). Likewise, a participant referenced the policies of Western countries for their emphasis on high-skilled immigrants, noting that "Educated people help raise the economy of the country...the United States and Europe took educated people. Why?" (Male 2 in Focus Group 2, 2018). Finally, when it came to reason for fleeing, participants emphasized both humanitarian and security concerns, noting both the importance of protecting refugees from persecution, but also that "we don't need troublemakers" (Female 3 in Focus Group 1, 2018). These discussions strengthen our confidence in the validity of the conjoint attributes as measures with relevance to our hypotheses about economic, cultural, and humanitarian concerns.

\section{Discussion}

Objectively, there is little doubt that the impact of the Syrian refugee crisis on Jordan has been significant. In the span of a few years, Jordan's population increased by nearly ten percent, in large part due to refugee inflows. This rapid increase exacerbated the country's pre-existing economic problems, including high unemployment, inadequate infrastructure, overburdened public services, and a deeply indebted government. With the exception of Lebanon and perhaps Turkey, no other country has been subject to so much strain as a result of the current refugee crisis. This experience is markedly different than in the West, where the number of refugees is relatively small in both

$18 \quad$ Anti-Shiite prejudices in Jordan are often encouraged by conservative religious groups for whom hostility toward Shiism is an important component of their ideology. They have also been bolstered by the regime: King Abdullah controversially labeled Shiite countries and organizations as a "Shia crescent" threatening the region, and the regime has remained fearful of Shiite political actors (Wagemakers, 2016). 
aggregate and proportional terms, and where economies also possess significantly more capacity to absorb refugees.

Jordan therefore provides a useful test that allows us to fill a gap in the existing literature: namely, the lack of studies on attitude formation toward migrant populations in developing contexts, which have been most affected by the current refugee crisis. Specifically, we use the Jordanian context to test existing theories about the importance of egocentric and sociotropic economic threats in shaping attitudes toward migrant populations. In contrast to findings from Western contexts, our study finds little evidence that egocentric or sociotropic economic concerns contribute substantially to Jordanians' views of Syrian refugees. Instead, we show evidence consistent with the importance of humanitarian and cultural factors. Jordanians with greater first-hand exposure to refugees and less sensitivity to cultural differences between themselves and others exhibited more positive views of Syrian refugees, and Jordanians across the board were more likely to prefer hosting refugees who were both vulnerable from a humanitarian standpoint and culturally similar to the host community.

The importance of these humanitarian and cultural factors suggests that, in the aggregate, Jordanian attitudes toward Syrians should be relatively positive, despite the significant economic impact of the refugee crisis on Jordan. After all, there is little question that Syrians have suffered greatly, and cultural differences between Jordanians and Syrians are minimal compared to many host and refugee populations elsewhere in the world. We argue that this pattern is visible in our top-line survey results. As shown in Figure 7, the overwhelming majority of respondents rate Syrians positively on the feeling thermometer and say that relations between the host and refugee communities are strong, suggesting little outright prejudice against the refugees. A majority of respondents also continue to endorse their country supporting and assisting Syrians, and majorities do not support closing the border to refugees or forcing those in Jordan to return to Syria. Majorities do want the government to move refugees to camps and to refrain from providing all refugees with work permits, suggesting opposition to integration. Furthermore, large majorities also believe that the impact of the refugee crisis on their country has been negative-particularly with regards to the economy and public services. Yet, these negative impact assessments may reflect a justifiable - and arguably accurate - perception of the effects of the refugee crisis on Jordan. The fact that many respondents articulate these negative opinions on impact while still describing refugees favorably 
and supporting efforts to assist them suggests that attitudes toward refugees remain relatively positive among the Jordanian public.

Our claim that Jordanians' attitudes toward Syrians remain relatively positive - particularly given the magnitude of the crisis - is reinforced through a comparison to public opinion in the United States and Europe at the height of the Syrian refugee crisis. While American and European attitudes toward migrants are often positive in the abstract (Rasmussen \& Poushter, 2019) —and have become more favorable since the peak of the refugee crisis in 2015 - attitudes toward Syrians in particular were generally negative. In 2015 and 2016, several surveys indicated that a majority of Americans did not want the United States to accept any refugees from Syria at all (Desilver, 2015; Kaplan, 2015; Smeltz et al., 2016). These attitudes were expressed at a time when the United States was admitting fewer than 100,000 refugees from all countries in a given year. In 2017, more than 80 percent of Americans identified Syrian and Iraqi refugees as a threat to the United States (Smith, 2017), and in Europe in 2016, majorities in Poland, Greece, Hungary, Italy, and the United Kingdom claimed that refugees from these countries were a "major" threat (Poushter, 2016). These attitudes contrast with attitudes in our survey described above, including the majority of Jordanians who did not support closing the border to refugees and supported ongoing efforts to host and assist Syrians, in addition to the large majority who expressed positive attitudes toward Syrian refugees on the feeling thermometer.

As a more systematic comparison of Jordanians' attitudes toward refugees to the attitudes of those in the West, we compare our conjoint results to a replication of findings from Bansak et al., (2016), who implement a similar conjoint design to study Europeans' views of asylum seekers at the peak of the refugee crisis. In their study, they plot the percentage of asylum seeker profiles accepted across the 15 European countries in their sample. We repeat this exercise in Jordan, showing that our respondents supported hosting - rather than removing - approximately 50 percent of Syrian refugee profiles. As shown in the Appendix, this percentage is higher than 13 of the 15 European countries studied in Bansak et al., with the exceptions of Italy and Spain. This comparison is not perfect: the conjoint attributes are similar but not identical across the two studies. Nonetheless, this pattern suggests that Jordanians in our survey remained more willing to entertain the idea of admitting refugees than many of their European counterparts, despite the heavier burden of the 


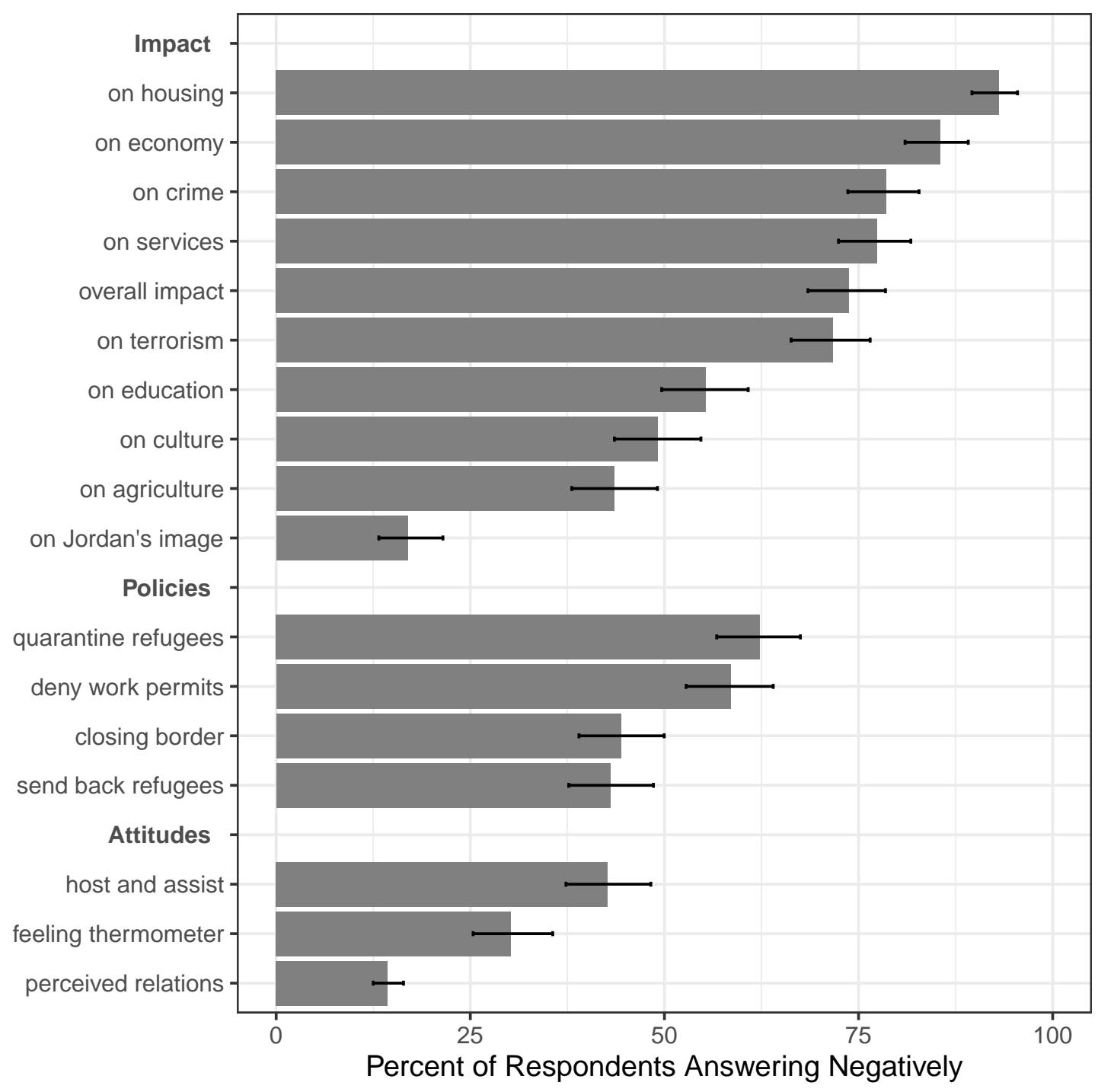

Figure 7: Attitudes toward refugees across outcome questions.

Note: This plot shows the percent of respondents whose answers indicated negativity toward refugees. 
Syrian refugee crisis on Jordan than any European country.

The importance of humanitarian and cultural factors in our study, in addition to the relatively positive attitudes of Jordanians toward Syrian refugees, suggest that humanitarian concerns can outweigh significant economic repercussions and sustain support for migrant populations, but primarily in contexts where cultures are similar. If many more of the refugees were Alawite or Christian, or perhaps if they were non-Arabs, attitudes toward the refugees would likely be more negative. Instead, they appear to have remained relatively positive because the shared cultural ties between Jordanians and Syrians helps humanitarian concerns to persist. This dynamic was articulated in our post-survey focus group discussions. One participant reflected on the entry of a low-skilled Syrian refugee used to working as a dustman, suggesting that the need to preserve his dignity outweighed the lack of economic benefit he would bring to Jordan. He asked, "Are we going to send him back because he's a scavenger?" He then noted that “...if the person is persecuted, we needn't add insult to injury. These people have to be received and have their dignity kept...we aren't to receive them because they are literate or not" (Male 2 in Focus Group 2, 2018). Another participant spoke similarly, observing how Jordanians "cared about the widows and children and forgot our problems, such as overcrowding and difficult financial conditions" (Female 1 in Focus Group 1, 2018).

Others succinctly summarized how cultural similarity facilitated this outcome. One stressed that "Jordan, Palestine, and Syria are all countries that share similar roots and characteristics which we received from our ancestors. Even if we want to be selfish, we cannot, because this is something deep inside us that we cannot help" (Female 5 in Focus Group 2, 2018). Likewise, a participant emphasized "the shared history among us," noting that "We're Muslims and we can't let them [Syrians] down" (Male 5 in Focus Group 2, 2018). A second participant responded positively to this comment, saying "Thank God we're born this way. We feel for others. And if a guest comes, we will be generous to them" (Female 6 in Focus Group 2, 2018).

At one point in the second focus group, respondents were asked explicitly to confront the apparent contradiction between a negative assessment of the refugees' impact on Jordan-particularly with regards to prices, housing, and jobs - and a continued willingness to describe Syrians favorably 
and welcome them into the country. One participant responded first that "there is no other place they [Syrians] can resort to. They are our brothers. We are required to take them in" (Female 2 in Focus Group 2, 2018). Another participant claimed that "...we can open the borders for them because this country is to serve them." He then followed up by noting that "We receive families who are Sunni. The others who are Shiite, we don't receive them. They are the source of trouble" (Male 3 in Focus Group 2, 2018). When someone responded to him by noting that Syrian Sunnis also raised prices, he countered by saying "Forget about the problems...among them [Syrians] are kids, elders, and women," and that "They can come in, even if I don't have enough to eat and my girls don't have enough to eat...I, as a Muslim, am obliged to open the door for my brother" (Male 3 in Focus Group 2, 2018). When two respondents then defended closing the border to new refugees, they were told that "If they [refugees] are women and kids, we should let them in, it's not fair to close the border on them" (Female 8 in Focus Group 2, 2018), that "We should let them in because above all they are humans" (Female 7 in Focus Group 2, 2018), and that "We really need to receive them even if they have a negative effect on us" (Female 5 in Focus Group 2). These conversations illustrate how the combination of humanitarian concerns and cultural similarity appears to have sustained a meaningful level of support for the refugees in the face of economic difficulties.

Lebanon provides an important counterexample that further reinforces this interpretation of our findings. Like Jordan, Lebanon has borne a significant burden as a result of the Syrian refugee crisis, but unlike Jordan, Lebanon is sharply divided between its Sunni, Shia, and Christian citizens. The influx of Syrian refugees has threatened to upend the fragile balance between these groups (Betts et al., 2017; Hagerdal, 2018). In the context of our findings, this greater cultural threat suggests that attitudes toward Syrian refugees should be more negative than those in Jordan. A number of sources support this expectation: in Lebanon, public attitudes toward refugees are more hostile, government policies are less generous, and politicians have actively incited negativity toward the Syrian population (Francis, 2017; Hagerdal, 2018).

One alternative explanation for our findings is that attitudes reflected in our survey are the result of Jordan's authoritarian political system, whereby Jordanians emphasized humanitarian concerns and minimized their expressions of hostile sentiments to avoid articulating opinions that might upset the government's narrative. This explanation is unlikely for several reasons. First, 
the Jordanian government has presented a narrative to the international community in which their hands are tied by a public frustrated with the refugees' presence; our survey results therefore do not clearly serve the government's interests. Second, Jordanians have a long history of contesting unpopular government policies, as demonstrated by protests against a proposed tax bill in May and June 2018 that resulted in the resignation of Prime Minister Hani Mulki. It is also not the case that economically vulnerable Jordanians are significantly less likely to articulate political views; in fact, protests during the Arab Spring were often driven by impoverished and marginalized rural communities (Yom, 2014). As a result, we do not think that the muted economic effects were driven by a general reluctance to express criticism, or greater reluctance among Jordanians most affected by the refugees' economic impact personally and in their communities. Finally, we included a battery of questions in the survey to measure respondents' sensitivity to social desirability bias. If concerns about respecting a pro-government narrative were salient to survey respondents, we would expect individuals more susceptible to social desirability bias to be particularly careful about their responses. However, we do not find meaningful differences between these subgroups (see Figure A.2 in the online appendix).

\section{Conclusion}

Our findings provide quantitative evidence on the factors that drive attitude formation toward migrant populations in a non-Western context, and as such have theoretical implications for the literature on this topic. As shown in Table 3, our findings reinforce the relevance of some existing theories while demonstrating limitations to others. First, given the impact of the refugee crisis on Jordan and its economy, the study provides evidence against theories emphasizing the importance of egocentric economic concerns as a major driver of anti-migrant sentiment. In particular, our results support a growing view that there is little evidence of egocentric concerns, even in a critical case where refugee inflows have a had major impact on the host country economy. Second, the results also call into question an emerging consensus on the relevance of sociotropic economic concerns. The absence of substantial effects in this regard is especially surprising, given the significant impact of the refugee crisis on Jordan and the large effects found in Western countries. These disparities 
point to a need for future research to examine when and why sociotropic economic concerns become influential in shaping attitudes toward migrant populations. The disparities also underscore the importance of paying close attention to issues of sample bias in published work and the need for research in additional unexplored contexts.

\begin{tabular}{|c|c|c|c|}
\hline Theory & Description & $\begin{array}{l}\text { Findings In } \\
\text { the West }\end{array}$ & $\begin{array}{c}\text { Findings in } \\
\text { Jordan }\end{array}$ \\
\hline $\begin{array}{l}\text { Egocentric } \\
\text { Economic } \\
\text { Concerns }\end{array}$ & $\begin{array}{l}\text { Fears of labor market } \\
\text { competition and other } \\
\text { personal economic threats } \\
\text { are a main driver of } \\
\text { attitudes toward migrants }\end{array}$ & $\begin{array}{c}\text { Mixed } \\
\text { Support }\end{array}$ & $\begin{array}{c}\text { No } \\
\text { Support }\end{array}$ \\
\hline $\begin{array}{c}\text { Sociotropic } \\
\text { Economic } \\
\text { Concerns }\end{array}$ & $\begin{array}{l}\text { Perceived threats to } \\
\text { country's economy and } \\
\text { services are a main } \\
\text { driver of attitudes } \\
\text { toward migrants }\end{array}$ & $\begin{array}{l}\text { Strong } \\
\text { Support }\end{array}$ & $\begin{array}{c}\text { Weak } \\
\text { Support }\end{array}$ \\
\hline $\begin{array}{l}\text { Cultural } \\
\text { Concerns }\end{array}$ & $\begin{array}{l}\text { Perceived threats to } \\
\text { country's culture } \\
\text { by cultural out-group } \\
\text { are a main driver of } \\
\text { attitudes toward migrants }\end{array}$ & $\begin{array}{l}\text { Strong } \\
\text { Support }\end{array}$ & $\begin{array}{l}\text { Strong } \\
\text { Support }\end{array}$ \\
\hline $\begin{array}{c}\text { Humanitarian } \\
\text { Concerns }\end{array}$ & $\begin{array}{l}\text { Sensitivity to } \\
\text { humanitarian } \\
\text { concerns is a main } \\
\text { driver of attitudes } \\
\text { toward migrants }\end{array}$ & $\begin{array}{c}\text { Mixed } \\
\text { Support }\end{array}$ & $\begin{array}{l}\text { Strong } \\
\text { Support }\end{array}$ \\
\hline
\end{tabular}

Table 3: Theories of Attitudes toward Migrants and Findings in Jordan

Secondly, our results bolster existing theories about the importance of perceived cultural threat in influencing attitudes toward migrant populations. On the one hand, the findings illustrate how sensitivity to cultural differences with migrants can generate negativity among the host population even in contexts where these differences are relatively slight. On the other hand, the findings also suggest that severe public backlash against migrants will be less likely to occur when migration takes place from countries in which cultural differences are less pronounced.

Lastly, our findings related to humanitarian concerns support a growing focus in the literature on the importance of humanitarianism in fostering sympathy for refugee and other migrant popu- 
lations. Practically, these results suggest that actors interested in promoting or maintaining social cohesion between host and refugee communities should explain and communicate the humanitarian plight of refugees, as well as their cultural similarity to the host community when applicable. Helping host communities around the world understand the extensive needs of refugee populations and reducing ignorance about different cultural practices may be viable strategies for shaping more positive public opinion toward migrant populations. With anti-refugee sentiment on the rise and no end in sight to the current migration crisis, exploring such an approach to building social cohesion is a promising area for future research.

\section{References}

Adepoju, A. (2003). Migration in West Africa. Development, 46 (3), 37-41.

Adida, C.L., Lo, A., \& Platas, M.R. (2019). Americans preferred Syrian refugees who are female, Englishspeaking, and Christian on the eve of Donald Trump's election. PLoS ONE, 14 (10).

Adida, C.L. (2011). Too Close for Comfort? Immigrant Exclusion in Africa. Comparative Political Studies, 44 (10), 1370-1396.

Ajlouni, S. \& Lockhart, D. (2019). The Syrian Refugee Crisis and Its Impact on the Jordanian Labour Market. WANA Institute. https://www.mercycorps.org/sites/default/files/3_ SyrianRefugeeCrisisImpactJordanianLabourMarket.pdf.

Al-Abed, M. (2017). Jordan allows Syrian children with no documents to join schools - officials. Jordan Times. http://jordantimes.com/news/local/ jordan-allows-syrian-children-no-documents-join-schools-\%E2\%80\%94-officials.

Al-Khalidi, S. (2018). Jordan ends bread subsidy, doubling some prices, to help state finances. Reuters. https://www.reuters.com/article/us-jordan-economy-subsidies-bread/ jordan-ends-bread-subsidy-doubling-some-prices-to-help-state-finances-idUSKBN1FF2CP.

Bansak, K., Hainmueller, J. \& Hangartner, D. (2016). How economic, humanitarian, and religious concerns shape European attitudes toward asylum seekers. Science, 14 (October), 217-222.

Bariagaber, A. (2006). Conflict and the Refugee Experience. London: Routledge. 
Becker, S.O., Fetzer, T., \& Novy D. (2017). Who voted for Brexit? A comprehensive district-level analysis. Economic Policy, 32 (92), 601-650.

Bencek, D \& Strasheim, J. (2016). Refugees welcome? A dataset on anti-refugee violence in Germany. Research and Politics, 3 (4), 1-11.

Bennet, D.H. (1988). The Party of Fear: From Nativist Movements to the New Right in American History. UNC Press Books.

Betts, A., Ali, A., \& Memisoglu, F. (2017). Local Politics and the Syrian Refugee Crisis: Exploring Responses in Turkey, Lebanon, and Jordan. Refugee Studies Center. https://www.rsc.ox.ac.uk/ files/files-1/local-politics-and-syrian-refugee-crisis_report-web.pdf.

Black, I. (2016). Jordan seals borders after suicide attack. The Guardian. https://www.theguardian.com/world/2016/jun/21/jordanian-soldiers-killed-by-car-bomb-outsidesyrian-refugee-camp.

Buehler, M. \& Han, K.J. (2019). Who Endorses Amnesty? An Original Survey from Morocco's Casablanca Region Assessing Citizen Support for Regularizing Clandestine Migrants. Review of Middle East Studies, 52 (2), 283-298.

Campbell, D.E. (2006). Religious "Threat" in Contemporary Presidential Elections. The Journal of Politics, 68 (1), 104-115.

Campbell, A.L., Wong, C., \& Citrin, J. (2006). Racial Threat, Partisan Climate, and Direct Democracy: Contextual Effects in Three California Initiatives. Political Behavior, 28, 129-150.

Card, D., Dustmann, C., \& Preston, I. (2012). Immigration, wages, and compositional amenities. Journal of European Economic Association, 10, 78-119.

Chandler, C.R. \& Tsai, Y. (2001). Social factors influencing immigration attitudes: an analysis of data from the General Social Survey. The Social Science Journal, 38 (2), 177-188.

Citrin, J., Green, D.P., Muste, C., \& Wong, C. (1997). Public Opinion Toward Immigration Reform: The Role of Economic Motivations. The Journal of Politics, 59 (3), 858-881.

Connor, P. (2018). Most displaced Syrians are in the Middle East, and about a million are in Europe. Pew Research Center. http://www.pewresearch.org/fact-tank/2018/01/29/where-displaced-syrians-haveresettled/. 
Dancygier, R. \& Donnelly, M.J. (2013). Sectoral economics, economic contexts, and attitudes toward immigration. Journal of Politics, 75, 17-35.

Desilver, D. (2015). U.S. public seldom has welcomed refugees into country.

Pew Research Center. https://www.pewresearch.org/fact-tank/2015/11/19/
u-s-public-seldom-has-welcomed-refugees-into-country/.

Dinas, E., Konstantinos, M., Xefteris, D., \& Hangartner, D. (2019). Waking Up the Golden Dawn: Does Exposure to the Refugee Crisis Increase Support for Extreme-right Parties? Political Analysis, 27 (2), 244-254.

Dunn, K.M., Klocker, N., \& Salabay, T. (2007). Contemporary racism and Islamaphobia in Australia: Racializing religion. Ethnicities, 7 (4), 564-589.

Dustmann, C. \& Preston, I.P. (2007). Racial and Economic Factors in Attitudes to Immigration. The B.E. Journal of Economic Analysis and Policy, 7 (1), 1-41.

Dustmann, C., Tommaso, F., \& Preston, I.P. (2012). The effect of immigration along the distribution of wages. Review of Economic Studies, 80 (1), 145-173.

Eastmond, M. \& Ascher, H. (2011). In the Best Interest of the Child? The Politics of Vulnerability and Negotiations for Asylum in Sweden. Journal of Ethnic and Migration Studies, 37 (8), 1185-1200.

Facchini, G. \& Mayda, A.M. (2009). Does the Welfare State Affect Individual Attitudes toward Immigrants? Evidence across Countries. The Review of Economics and Statistics, 91 (2), 295-314.

Foged, M. \& Peri, G. (2016). Immigrants' effect on native workers: New analysis on longitudinal data. American Economic Journal: Applied Economics, 8 (2), 1-34.

Francis, A. (2015). Jordan's Refugee Crisis. Carnegie Endowment for International Peace. https: //carnegieendowment.org/files/CP_247_Francis_Jordan_final.pdf.

Francis, E. (2017). Hostility grows towards Syrian refugees in Lebanon. Reuters. $\quad$ https://www.reuters.com/article/us-lebanon-refugees-tension/ hostility-grows-towards-syrian-refugees-in-lebanon-idUSKCN1B8128.

Frey, B.S., Savage, D.A., \& Torgler, B. (2010). Interaction of natural survival instincts and internalized social norms exploring the Titanic and Lusitania disasters. PNAS, 107 (11), 4862-4865.

Frontani, H.G., Silvestri, K. \& Brown, A. (2009). Media Image and Social Integration of Liberian and Togolese Refugees in Ghana. Africa Media Review, 17 (1-2), 51-75. 
Ghosn, F., Braithwaite, A., \& Chu, T.S. (2018). Violence, displacement, contact, and attitudes toward hosting refugees. Journal of Peace Research, 56 (1), 118-133.

Glatz, C. (2014). Syrian Christian refugees fleeing to Jordan on the rise, Caritas says. Catholic News Service. http://www.catholicnews.com/services/englishnews/2014/ syrian-christian-refugees-fleeing-to-jordan-on-the-rise-caritas-says.cfm.

Grabska, K. (2006). Marginalization in Urban Spaces of the Global South: Urban Refugees in Cairo. Journal of Refugee Studies, 19 (3), 287-307.

Hagerdal, N. (2018). Lebanon's Hostility to Syrian Refugees. Crown Center for Middle East Studies, Middle East Brief. https://www.brandeis.edu/crown/publications/meb/MEB116.pdf

Hainmueller, J., Hangartner, D., \& Lawrence, D. (2016). When lives are put on hold: Lengthy asylum processes decrease employment among refugees. Science Advances, 2 (8).

Hainmueller, J. \& Hopkins, D.J. (2015). The hidden American immigration consensus: A conjoint analysis of attitudes toward immigrants. American Journal of Political Science, 59 (3), 529-548.

Hainmueller, J. \& Hopkins, D.J. (2014). Public Attitudes Toward Immigration. Annual Review of Political Science, 17, 225-249.

Hainmueller, J., Hopkins, D.J. \& Yamamoto, T. (2014). Causal Inference in Conjoint Analysis: Understanding Multidimensional Choices via Stated Preference Experiments. Political Analysis, 22 (1), $1-30$.

Hainmueller, J. \& Hiscox, M.J. (2010). Attitudes toward highly skilled and low-skilled immigration: evidence from a survey experiment. American Political Science Review, 104 (1), 61-84.

Hainmueller, J. \&Hiscox, M.J. (2007). Educated Preferences: Explaining Individual Attitudes Toward Immigration in Europe. International Organization, 61 (2), 399-442.

Hainmueller, J., Hiscox, M.J., \& Margalit, Y. (2015). Do concerns about labor market competition shape attitudes toward immigration? New evidence. Journal of International Economics, 97 (1), 193-207.

Hangartner, D., Dinas, E., Marbach, M., Konstantinos, M. \& Xefteris, D. (2019). Does Exposure to the Refugee Crisis Make Natives More Hostile? American Political Science Review, 113 (2), 442-455.

Hartman, A.C., \& Morse, B.S. (2018). Violence, Empathy, and Altruism: Evidence from the Ivorian Refugee Crisis in Liberia. British Journal of Political Science. 
Hopkins, D.J. (2010). Politicized Places: Explaining Where and When Immigrants Provoke Local Opposition. American Political Science Review, 104 (1), 40-60.

Hruschka, C. \& Leboeuf, L. (2019). Vulnerability: A Buzzword or a Standard for Migration Governance? Max Planck Society and Population Europe. Population and Policy Compact 20.

Husseini, R. (2018). 7.3b Jordan Response Plan endorsed. The Jordan Times. http://www . jordantimes . com/news/local/73b-jordan-response-plan-endorsed

IRI. (2016). Survey of Jordan Public Opinion: National Poll \# 14. http://www.iri.org/sites/default/ files/iri_national_poll_14___november_23-27_2016_.pdf.

Kaplan, R. (2015). Poll: Majority of Americans say end Syrian refugee program. CBS News. https: //www.cbsnews.com/news/poll-majority-of-americans-say-end-syrian-refugee-program/.

Kalkan, K.O., Layman G.C., \& Uslaner, E.M. (2009). Bands of Others? Attitudes toward Muslims in Contemporary American Society. Journal of Politics, 71 (3), 1-16.

Kao, K. (2015). Ethnicity, Electoral Institutions, and Clientelism: Authoritarianism in Jordan. PhD thesis, UCLA.

Kayyali, S. (2017). Syrian Refugees Trapped in A No Man's Land. Human Rights Watch. https://www. hrw.org/news/2017/12/06/syrian-refugees-trapped-no-mans-land.

Kingsley, P. (2015). Over a million migrants and refugees have reached Europe this year, says IOM. The Guardian. https://www.theguardian.com/world/2015/dec/22/ one-million-migrants-and-refugees-have-reached-europe-this-year-iom.

Levitan, R., Kaytaz, E. \& Durukan, O. (2009). Unwelcome Guests: The Detention of Refugees in Turkey's "Foreigners' Guesthouses. Refuge, 26 (1), 77-90.

Lie, J. (2019). East Asian Exceptionalism to Western Populism and Migration Crisis. In Oxford Handbook of Migration Studies. Eds. Cecilia Menjivar, Marie Ruiz, and Immanuel Ness. Oxford University Press.

Lockhart, D. \& Dryden, J. (2018). Syrian Refugee Labour Inclusion Policy in Jordan: Emerging Trends Two Years In. WANA Institute. https://www.mercycorps.org/sites/default/files/6_ SyrianRefugeeLabourInclusionPolicyJordanWANA.pdf.

Luck, T. (2013). In Jordan, tensions rise between Syrian refugees and host community. The Washington Post. https://www.washingtonpost.com/world/middle_east/ 
Lust-Okar, E. (2006). Elections under authoritarianism: Preliminary lessons from Jordan. Democratization, 13 (3), 456-471.

Malka, Ariel, Christopher J. Soto, Adam B. Cohen, and Dale T. Miller. 2011. "Religiosity and Social Welfare: Competing Influences of Cultural Conservatism and Prosocial Value Orientation." Journal of Personality 79 (4): 763-792.

Malkawi, K. (2016). Jordan's public sector largest worldwide in relative terms.

The Jordan Times. http://www.jordantimes.com/news/local/jordan\%E2\%80\%

99s-public-sector-largest-worldwide-relative-terms $\%$ E2\%80\%99.

Martin, A. (2005). Environmental Conflict Between Refugee and Host Communities. Journal of Peace Research, 42 (3), 329-346.

Mayda, A.M. (2006). Who Is Against Immigration? A Cross-Country Investigation of Individual Attitudes toward Immigration. The Review of Economics and Statistics, 88 (3), 510-530.

Medecins Sans Frontieres. (2018). Jordan: Syrians access to medical care at risk. http://www.msf.org/ en/article/jordan-syrians-access-medical-care-risk

Newman, B.J. (2013). Acculturating Contexts and Anglo Opposition to Immigration in the United States. American Journal of Political Science, 57 (2), 374-390.

Newman, B.J., Hartman, T.K., Lown, P.L. \& Feldman, S. (2015). Easing the Heavy Hand: Humanitarian Concern, Empathy, and Opinion on Immigration. British Journal of Political Science, 45 (3), 583-607.

Norman, K.P. (2019). Inclusion, Exclusion, or Indifference? Redefining Migrant and Refugee Host State Engagement in Mediterranean 'Transit' Countries. Journal of Ethnic and Migration Studies, 45 (1), $42-60$.

Norman, K.P. (2016). Migrants, Refugees, and the Egyptian Security State. International Journal of Migration and Border Studies, 2 (4), 345-364.

Onoma, A.K. (2013). Anti-Refugee Violence and African Politics. Cambridge University Press.

Poushter, J. (2016). European opinions of the refugee crisis in 5 charts. Pew Research Center. https://www.pewresearch.org/fact-tank/2016/09/16/ european-opinions-of-the-refugee-crisis-in-5-charts/. 
Rasmussen, R. \& Poushter, J. (2019). People around the world express more support for taking in refugees than immigrants. Pew Research Center. https://www.pewresearch.org/fact-tank/2019/08/09/ people-around-the-world-express-more-support-for-taking-in-refugees-than-immigrants/

Robbins, Mi. and Rubin, L. (2013). The Rise of Official Islam in Jordan. Politics, Religion 83 Ideology, 14 (1), 59-74.

Ryan, C. (2010). We Are All Jordan...But Who is We? Middle East Research and Information Project. https://www.merip.org/mero/mero071310.

Ryan, C. (2018). Jordan and the Arab Uprisings. Columbia University Press.

Scheve, K.F. \& Slaughter, M.J. (2001). Labor Market Competition and Preferences Over Immigration Policy. The Review of Economics and Statistics, 83 (1), 133-145.

Silverstein, M \& Parrott, T.M. (1997). Attitudes Toward Public Support of the Elderly. Research on Aging, 19 (1), 108-132.

Smeltz, D., Kafura, C., \& Martin, K. (2016). Americans Support Limited Military Action in Syria against ISIS. The Chicago Council on Global Affairs. https://www.thechicagocouncil.org/publication/ americans-support-limited-military-action-syria-against-isis.

Smith, S. (2017). Young people less likely to view Iraqi, Syrian refugees as major threat to U.S. Pew Research Center. https://www.pewresearch.org/fact-tank/2017/02/03/ young-people-less-likely-to-view-iraqi-syrian-refugees-as-major-threat-to-u-s/.

Sniderman, P,M., Hagendoorn, L., \& Prior, M. (2004). Predisposing Factors and Situational Triggers: Exclusionary Reactions to Immigrant Minorities. American Political Science Review, 98 (1), 35-49.

Steinmayer, A. (2018). Contact Matters: Exposure to Refugees and Voting for the Far-right. Working Paper. https://docs.google.com/viewer?a=v\&pid=sites\&srcid= ZGVmYXVsdGRvbWFpbnxhbmRyZWFzc3RlaW5tYXlyfGd40jcyYzAxMjA0ZWRhODJmZGI.

Stave, S.E. \& Hillesund, S. (2015). Impact of Syrian refugees on the Jordanian labour market. International Labor Organization. https://www.ilo.org/wcmsp5/groups/public/Carabstates/ @ro-beirut/documents/publication/wcms_364162.pdf

Steenbergen, M.R. (2004). Compassion and American Public Opinion: An Analysis of the NES Humanitarian Scale. Report to the Board of Overseers of the National Election Stud- 
ies. https://pdfs.semanticscholar.org/54ad/fa4a51cbe8dccb8314c8ffeee79237e8d854.pdf? _ga=2.101958657.1401959029.1553274575-1857978767.1553044190.

Su, A. (2017). Why Jordan is Deporting Syrian Refugees. The Atlantic. https://www .theatlantic . com/ international/archive/2017/10/jordan-syrian-refugees-deportation/543057/.

Tesler, M. (2015). Priming Predispositions and Changing Policy Positions: An Account When Mass Opinion is Primed or Changed. American Journal of Political Science, 59 (4), 806-824.

UNHCR. (2018). Mid-Year Trends 2017. https ://www. unhcr.org/5aaa4fd27.pdf.

UNHCR. (2017). Migrants in Vulnerable Situations: UNHCR's Perspective. https://www.refworld. org/pdfid/596787174.pdf

UNHCR. (2015). Women on the Run. https://www.unhcr.org/about-us/background/56fc31864/ women-on-the-run-full-report.html.

Valentino, N.A., Soroka, S.N., Iyengar, S., Aalberg, T., Duch, R., Faile, M., Hahn, K.S., Hansen, K.M., Harell, A., Helbling, M., Jackman, S.D., \& Kobayashi, T. (2019). Economic and Cultural Drivers of Immigrant Support Worldwide. British Journal of Political Science, 49 (4), 1201-1226.

Wagemakers, J. (2016). Anti-Shi'ism without the Shi'a: Salafi Sectarianism in Jordan. Maydan. https://www.themaydan.com/2016/10/ anti-shiism-without-the-shia-salafi-sectarianism-in-jordan/

Williamson, S. (2019). Separating Islam from Politics But Not the State: Implications for Religious Authority in Jordan. Baker Institute for Public Policy. https://www.bakerinstitute.org/media/ files/files/a65139aa/cme-pub-luce-williamson-030719.pdf

Yom, S. (2014). Tribal Politics in Contemporary Jordan: The Case of the Hirak Movement. Middle East Journal, 68 (2), 229-247.

Zhao, Y. (2018). Refugee Proximity and Support for Citizenship Exclusion in Africa. Working Paper. https://static1.squarespace.com/static/53d71184e4b0653934832e81/t/ 5b8b2ca5aa4a99a49825eeae/1535847594886/Zhou_CitiExclusion.pdf. 